\title{
$\int_{0}^{0 / 7^{50}} \quad D F^{-1020-0}$ \\ $I-2 / 05 /$ uCD-20405.
}

\section{PHYSICS MODELING OF TANDEM MIRROR DEVICES WITH HIGH-F IELD TEST CELL INSERTS}

M. E. Fenstermacher

R. B. Campbe 11

Aprif 15,1985
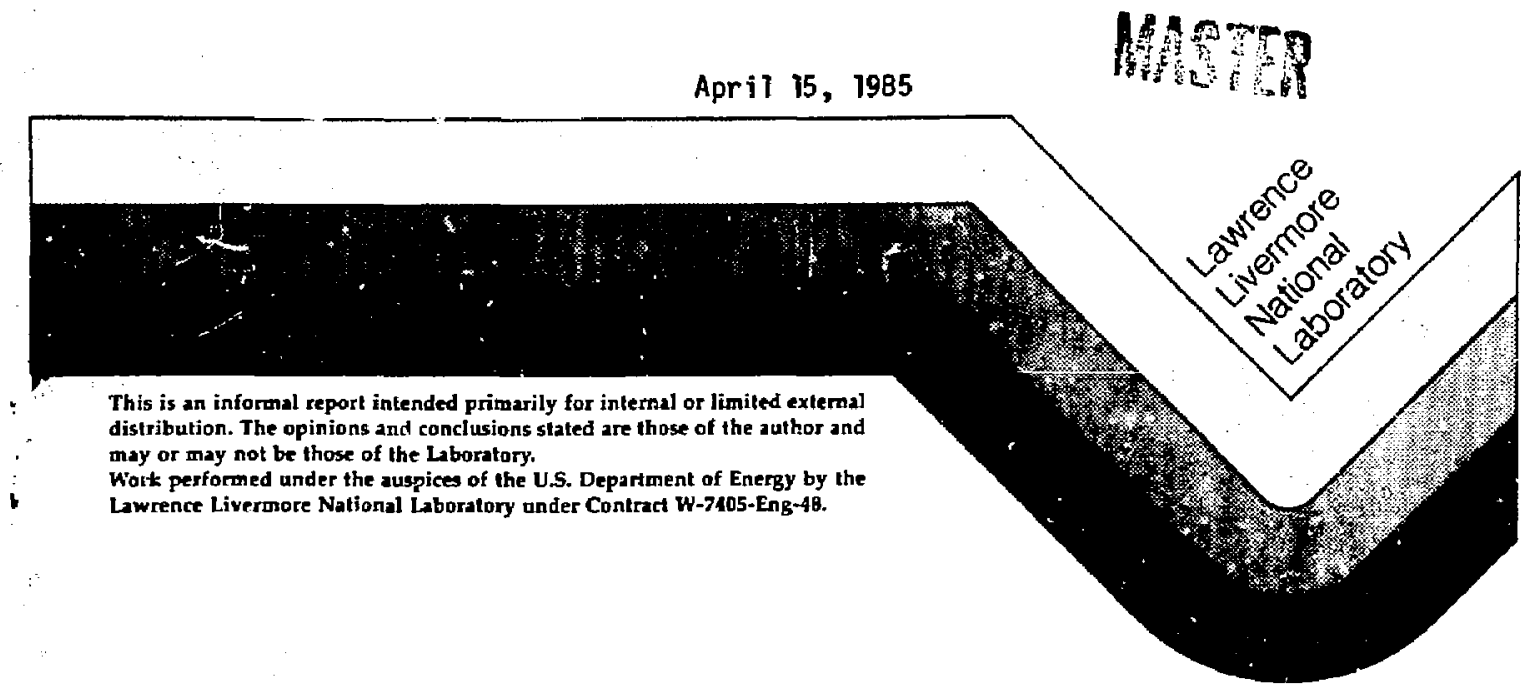

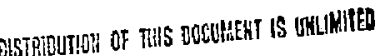




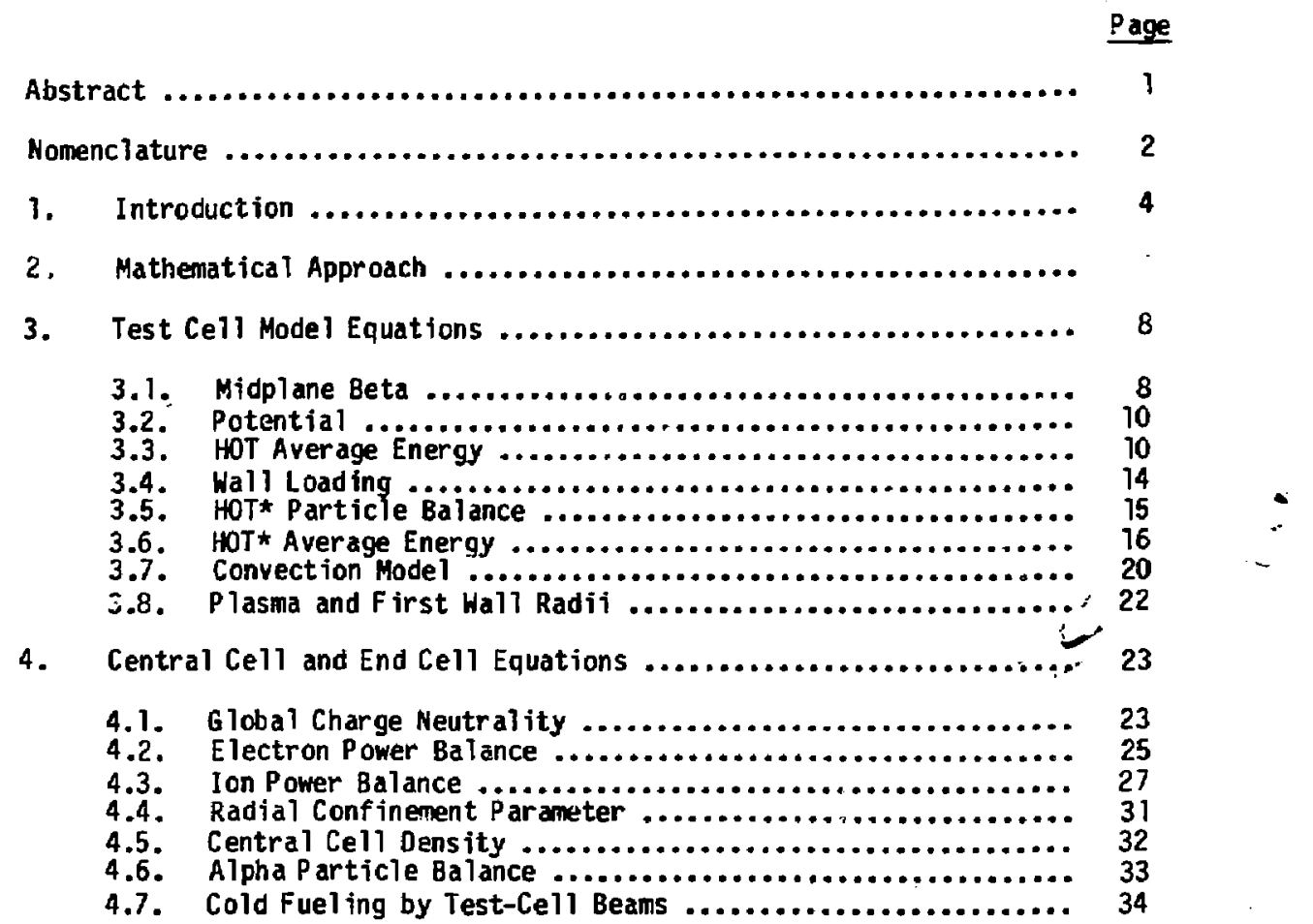

5. Auxiliary Models .................................... 35

5.1. Charge Exchange Model ............................. 35

5.2. Hot Ion $<\sigma y\rangle_{H}$ Parameters .......................... 38

5.3. Alpha $P$ article and Energy Coefficients $\ldots \ldots \ldots \ldots \ldots \ldots \ldots \ldots . . . \ldots$

5.4. Direct Converter Heat F lux .......................... 41

6. User's Guide $\ldots \ldots \ldots \ldots \ldots \ldots \ldots \ldots \ldots \ldots \ldots \ldots \ldots \ldots \ldots \ldots \ldots \ldots \ldots, 42$

6.1. input Requirements ................................ 43

6.2 . Output File $\ldots \ldots \ldots \ldots \ldots \ldots \ldots \ldots \ldots \ldots \ldots \ldots \ldots \ldots \ldots \ldots \ldots \ldots \ldots \ldots, 45$

6.3. Comments on Running ................................ 47

7. Benchmark Case .................................... 47

8. Sumary $\ldots \ldots \ldots \ldots \ldots \ldots \ldots \ldots \ldots \ldots \ldots \ldots \ldots \ldots \ldots \ldots \ldots \ldots \ldots \ldots . \ldots \ldots$

8.1. Conrilusions ................................. 54

8.2. Future Work .................................. 54 
Appendix A. Test Cell Code 0 tions ........................ 57

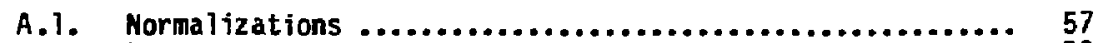

A.2. Calculation Options .............................. 58

References ............................................... 60 
PHYSICS MODELIHG OF TANDEM MIRROR DEVICES WITH

HIGH-FIELD TEST CELL INSERTS

M. E. Fenstermacher*

R. B. Campbe1\}*

TRH Inc.

Redondo Beach, CA 90278

\section{ABSTRACT}

Recently developed plasma physics models of tandem mirror operation with a high-field technology test cell insert in the central cell are described in detail. These models have been incorporated in the TMRBAR tandem mirror reactor physics code. Results of a benchmark case for the code models aga inst previous analysis of the MFTF- $\alpha+T$ configuration are given. A brief users guide to the new TMRBAR with the test cell models is also presented. Some description of the applications of the models to MFTF-a+T and FPD-II+T configurations is made. References are given to separate reports on these studies.

*0n ass ignment to Lawrence Livermore National Laboratory, Livermore, CA 94550. 
The following is a brief list of the frequentiy used variables in the test cell models.

\begin{tabular}{|c|c|c|c|}
\hline Variable & $\begin{array}{l}\text { Variable } \\
\text { Name }\end{array}$ & Unit & Descriptjon \\
\hline $\mathbf{n}_{\mathbf{H}}$ & ENMHOTO & $\mathrm{cm}^{-3}$ & HOT ion density \\
\hline $\mathbf{n}_{H}^{*}$ & ENHOTSTR & $\mathrm{cm}^{-3}$ & HOT* ion density \\
\hline$E_{H}$ & EMHOTBAR & keV & HOT ion average energy \\
\hline$E_{H}^{*}$ & EMSTRBAR & keV & HOT* ion average energy \\
\hline$n_{c}$ & ENC & $\mathrm{cm}^{-3}$ & COLD ion density \\
\hline$T_{c}$ & TC & $\mathrm{ker}$ & COLD ion temperature \\
\hline Tec & TECU & $\mathrm{keV}$ & electron temperature \\
\hline$(n \tau)_{P C}$ & ENTAUPC & $\mathrm{cm}^{3} \mathrm{~s}$ & particle confinement parameter in test cell \\
\hline$(n)_{P C C}$ & ENTAUPCC & $\mathrm{cm}^{3} \mathrm{~s}$ & $\begin{array}{l}\text { particle conf inement parameter for HOT* } \\
\text { in central cel? }\end{array}$ \\
\hline$v_{m}$ & VMOD & $\mathrm{cm}^{3}$ & test cell volume \\
\hline$L_{m, e f f}$ & ELMOD & $\mathrm{cm}$ & test cell $\mathrm{n}^{2}$ effective length \\
\hline$r_{\bmod }$ & RMCD & & test cell plasma radius \\
\hline $\mathbf{q}$ & ECHARGE & $\mathrm{kJ} / \mathrm{keV}$ & e lectronic charge $=1.602 \times 10^{-19} \mathrm{~kJ} / \mathrm{keV}$ \\
\hline$\Phi_{\mathrm{mo}}$ & PHIMO & kV & test cell potential above $\phi_{e}$ \\
\hline$B_{m 0, v a c}$ & BMOVAC & $\mathbf{T}$ & test cell vacuum midplane field \\
\hline$B_{m m, v a c}$ & BMMYAC & $T$ & test cell peak field \\
\hline$B_{\mathrm{mO}}$ & BETAMO & - & test cell midplane peak beta \\
\hline$\overline{\mathrm{E}}_{\text {INJ }}$ & EINJM & keV & $\begin{array}{l}\text { test cell neutral beam average injection } \\
\text { energy }\end{array}$ \\
\hline
\end{tabular}


Nomenclature for central cell and end cell variables will follow

Ref. 1. Default units used throughout this report are as follows:

Quantity

Density

Temperature, energy

Potential

Magnet ic field

Length, radius (etc.)

Volunie
Unit

$$
\mathrm{cm}^{-3}
$$

keV

kV

$T$

cm

$\mathrm{cm}^{3}$ 


\section{INTRODUCTION}

The purpose of this report is to document models of tandem mirror operation with high-field, beam-driven technology test-cell inserts, which have been developed recentTy at LLNL. The mode 15 have been incorporated in the TMRBAR tandem mirror reactor physics code. (1) So far results have been obtained only for devices with MARS-type double yin-yang end cells though the test cell models are not restricted to devices of this type.

A high-field beam driven test cell inserted in the central cell of a tandem mirror device can be used to do inte;rated technology testing of fusion reactor components (blankets, shields, structural components etc.) in a fusion environment. Reactor like conditions (high wall loading and fusion power density) are achieved in the test cell region by injecting large currents of mixed deuterium-tritium neutral beams. When test cell operation is proposed as an upgrade of an existing tandem mirror device which has been designed for high-Q operation with good axial plugging, it is desirable that the required modifications of the end cell systems be kept to a min inum to reduce the cost of the upgrade. In these cases, steady state is obtained by adjusting the axial potential profile to reduce the axial confinement thereby providing a loss channel for the injected beam current.

This report will serve both as a reference to the physics modeis of the test-cell operation and as a users guide to the upgraded TMRBAR code. Improvements in the TMRBAR models of devices without test-cell inserts which have been made since the writing of Ref. 1 will be given in a separate report. (2) Applications of the test cell models to MFTF- $\alpha+T$ and the FPD-II+T devices have been presented in detail elsewhere ${ }^{(3,4)}$ and will be described only briefly here.

The remainder of th is report is organized as follows: Section 2 gives an overview of the mathematical approach to modeling test-cell operation. The detailed equations for the test-cell models are given in Sec. 3. The changes in the equations for the central cell and end cell models which are required when the test cell is aoded to the device are presented in Sec. 4. Section 5 gives several auxiliary models used to complete the device description. A brief users guide to the upgraded TMRBAR code is presented in Sec. 6 followed 
by results from a benchmark case for the code in Sec. 7. A summary of the work including conclusions and areas for future work is given in Sec. 8 .

\section{MATHEMATICAL APPROACH}

The TMRBAR models of tandem mirror physics have been upgraded to include test-cell physics by adding energy and particle balances of the plasma ions for a cardinal point at the midplane of the test cell. The ion and electron balances for the remainder of the device have been modified to include testcell effects. The test cell is treated as a separate subsystem of the device similar to the way in wich the end cells are treated. The self-consistent potential for the test-cell cardinal point relative to the potential in the remainder of the central cell is calculated from a quasi-neutrality conaition. Typical potential and magnetic field profiles for devices with test-cell inserts are shown in Fig. 1.

The velocity space for ions at the midplane of the test cell is illustrated in Fig. 2. Three classes of ions can be identified. HoT ions are those which are mirror trapped between the test-cell peak mirror fielos. HOT* ions are those with pitch angle and energy such that they are not mirror trapped in the test cell but remain trapped by the central cell peak chokecoil fields. COLD ions are assumed to form a Maxwellian distribution in the central cell region. Part of this population passes the choke coil point into the end cell region and is electrostatically confined by the potential peak in the plug. The remainder is mirror trapped in the central cell. To further aistinguish the HOT* population from that part of the COLD distribution which remains in the central cel1, the specification is made that the HOT* ion carries sufficient energy that if it pitch angle scatters at fixed energy into the loss cone for the central cell mirror, it is not confined by the electrostatic plugging potential and is lost axially from the device.

$P$ article and energy balances for the HOT and HOT* ions have been modeled us ing modified Logan-Rensink plug models $(5,6)$ for bear ions injected into a magnetic trap with a potential. Particie flow across the boundaries in Fig. 2 and energy transfer from the hot populations to the background plasma are included. In addition, a crude model of the convection of energy due to 


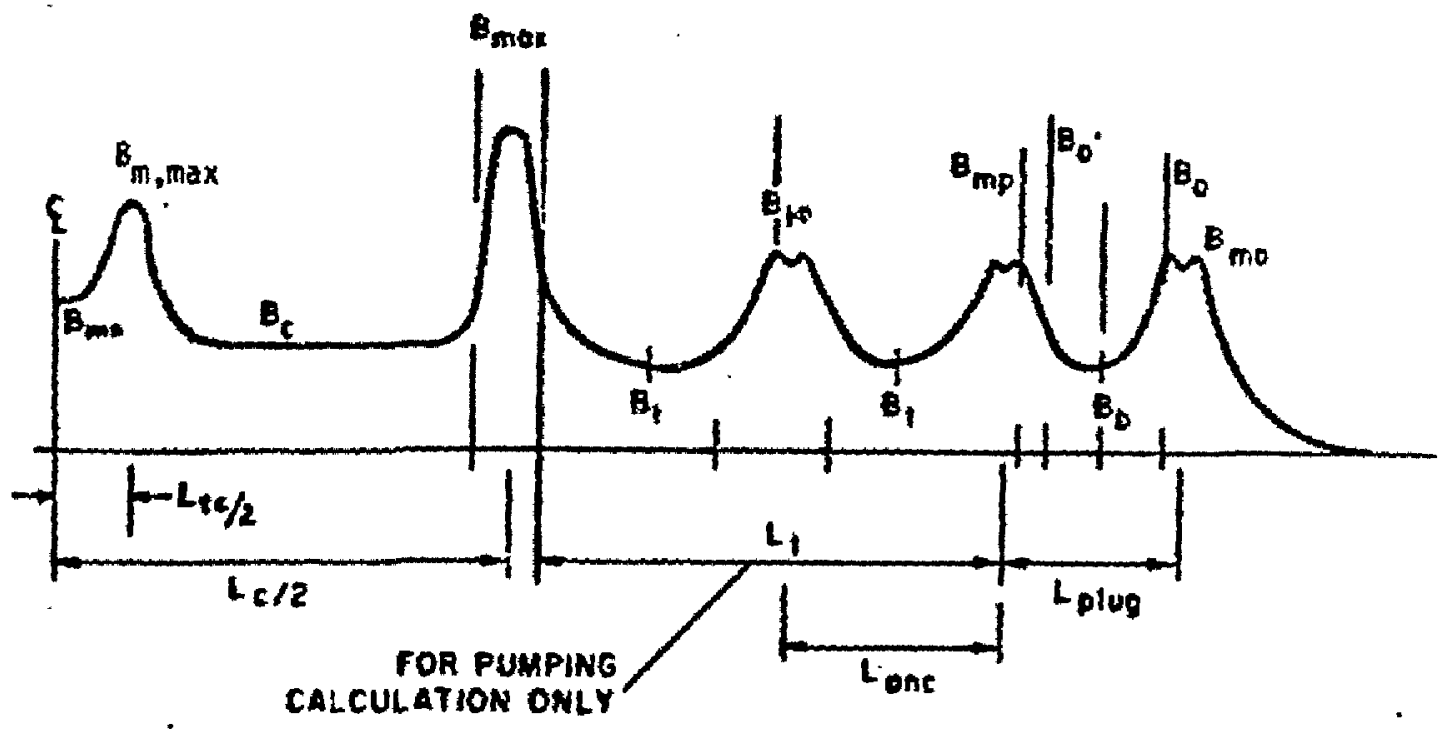

Fig. la. $B(z)$ and lengths definitions (not to scale).

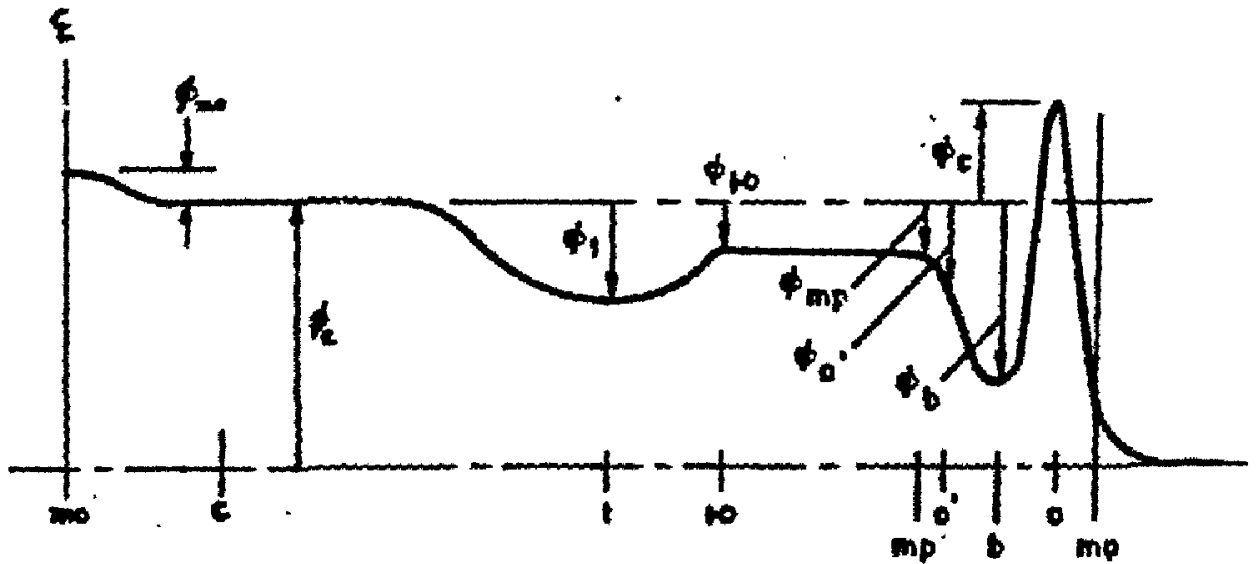

Fig. lb. $\phi(z)$ definitions (not to scale). 


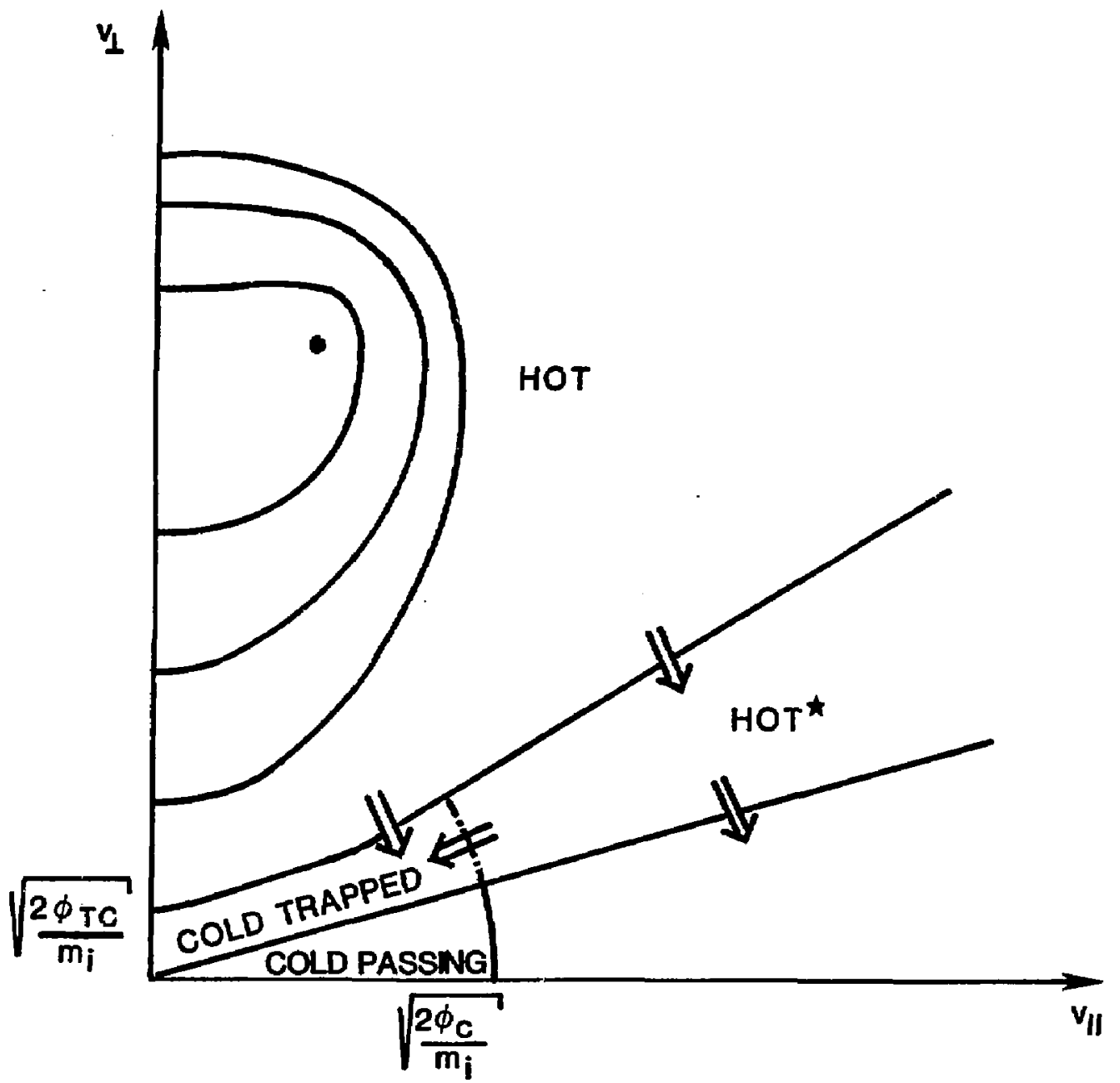

Fig. 2. Velocity space for ions at the midplane of the test cell. 
particles crossing the boundaries in velocity space at energies:igher than the COLD temperature has been developed. Finally, energy from hot fusion alpha particles slowing down in the test cell has been included in the ion and electron energy balances.

\section{TEST CELL MODEL EqUATIONS}

Physics parameters for tandem mirror devices are calculated by the TMRBAR code by solving $N$ non-l inear equations, describing the physical processes in the central cell and end cells, in $N$ independent physics variables. To model test-cell operation, six additional equations in six new independent variables have been added. The equations calculate test cell beta, potential (relative to the central cell potential), and neutron wall loading as well as describing the energy balance for the HOT particles ano the particle and energy balances for the HOT* particles. The independent variables used are the HOT and HOT* densities, test cell wall loading and potential, and the HOT and HOT* average energies.

\section{1. Midplane Beta}

The equation for beta at the midplane of the test cell is

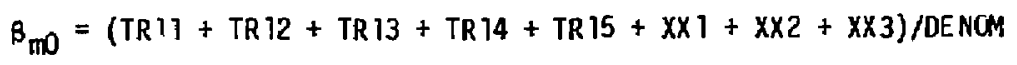

where

$$
\begin{aligned}
& \text { TR11 }=0.8 n_{H} \bar{E}_{H} \\
& T R 12=n_{e c} \exp \left(\phi_{m 0} / T_{e c}\right) T_{e c} \\
& T R_{13}=n_{c} \exp \left(-\phi_{m 0} / T_{c}\right) T_{c} \\
& T_{4}=2 n_{c} C_{\alpha} \exp \left(-2 \Phi_{m 0} / T_{\alpha, A V G}\right) T_{\alpha, A V G}
\end{aligned}
$$




$$
\begin{aligned}
& T R 15=0.735 n_{H}^{*} \overline{E_{H}^{t}} \\
& X X 1=8.3 \times 10^{10}\left\langle\sigma v\left(E_{H}\right)\right\rangle_{H} T_{e c}^{3 / 2} U_{D T, \alpha} f_{\alpha, e m} n_{H}^{2} / n_{e m} \\
& x X ?=8.3 \times 10^{10}\left\langle\sigma v\left(T_{c}\right)\right\rangle T_{e c}^{3 / 2} U_{D T, \alpha} f_{\alpha, e m}\left[n_{c} \exp \left(-\phi_{m 0} / T_{c}\right)\right]^{2} / n_{e m} \\
& x x 3=8.3 \times 10^{10}\left\langle\sigma v\left(\overline{E_{H}^{-}}\right)\right\rangle_{H} T_{e c}^{3 / 2} U_{D T, \alpha} f_{\alpha, e m}\left(n_{H}^{*}\right)^{2} / n_{e m}
\end{aligned}
$$

and

$$
\text { DENOM }=B_{m 0, V A C}^{2} / 2 \mu=2.483 \times 10^{15} B_{m 0, V A C}^{2}
$$

The electron density in the central cell is given by

$$
n_{e c}=n_{c}\left(1+2 c_{\alpha}\right)+n_{H}^{*}
$$

and the soncentration of thermal alpha ash in the central cell is defined as

$$
c_{\alpha}=n_{\alpha} / n_{c}
$$

where $n_{\alpha}$ is the thermal alpha density. The average alpha temperature is given by

$$
T_{\alpha, A \cup G}=C_{1} T_{c}+C_{2} \bar{E}_{H}+C_{3} \overline{E_{H}^{\bar{H}}}
$$

where

$$
\begin{aligned}
& c_{1}=n_{c} /\left(n_{H}+n_{H}^{*}+n_{c}\right) \\
& c_{2}=n_{H} /\left(n_{H}+n_{H}^{*}+n_{C}\right) \\
& c_{3}=n_{H}^{*} /\left(n_{H}+n_{H}^{*}+n_{c}\right)
\end{aligned}
$$


In the hot alpha pressure terms [Eqs. (3.7) - (3.9)] the alpha birth energy $U_{D T, \alpha}=3.52 \mathrm{MeV}$ and $f_{\alpha, e m}$ is the fraction of alpha energy given to the electrons during slcwing down (see Sec. 4). The electron density in the test cell is given by

$$
\begin{aligned}
n_{e m}= & n_{H}+n_{H}^{\star}+n_{c} \exp \left(-\phi_{m 0} / T_{c}\right) \\
& +2{ }_{n c} C_{\alpha} \exp \left(-2 \phi_{m 0} / T_{\alpha, A V G}\right)
\end{aligned}
$$

The reaction rate for mirror trapped ion distributions $\angle \sigma v(E)\rangle_{H}$ is described in Sec. 5.2 .

\subsection{Potential}

The potential at the test cell midplane relative to the central cell potential is obtained from a quasi-neutrality condition of the form

$$
n_{\mathrm{em}}=n_{\mathrm{ec}} \exp \left(\phi_{\mathrm{n} 0} / T_{\mathrm{ec}}\right)
$$

\subsection{Hot Average Energy}

The average energy of the HOT ions which are mirror trapped in the test ce 11 is obtained from a Logan-Rensink plug mode $\mathrm{l}^{(5,6)}$ for beam injected ions in a mirror magnetic field with a potential. The energy balance in this model takes the form

$$
\left.\frac{q V_{M C D}}{1000}(T R 3)-T R 32-T R 33+T R 34+T R 35+T R 36-T R 37\right)=0
$$

where

$$
\begin{aligned}
& \text { TR31 }=\overline{n_{H} n_{\text {en }}}\left(\bar{E}_{I N J}-\bar{E}_{L, H O T}\right) /(n \tau)_{P C} \\
& T R 32=\overline{n_{H}^{n} \text { em }}\left(\bar{E}_{H}-\frac{3}{2} T_{e c}\right) /(n \tau)_{H e}
\end{aligned}
$$




$$
\begin{aligned}
& \text { TR33 }=\overline{n_{H} n_{C}} \exp \left(-\phi_{m 0} / T_{C}\right)\left[E_{H}-\frac{3}{2} T_{c}\right] /(n \tau)_{H C} \\
& T R 34=\frac{1}{4} \overline{n_{H}^{2}}\left\langle\sigma v\left(E_{H}\right)\right\rangle_{H} E_{\alpha, H 0 T}^{H H} \\
& T R 35=\frac{1}{4} \overline{\left[n_{c} \exp \left(-\phi_{m 0} / T_{c}\right)\right]^{2}}\left\langle\sigma v\left(T_{c}\right)\right\rangle E_{\alpha, H O T}^{c c} \\
& T R 36=\frac{1}{4} \overline{\left(n_{A}\right)^{2}}\left\langle\sigma v\left(\overline{E_{A}}\right)\right\rangle_{H} E_{\alpha, H O T}^{\star \star *} \\
& \operatorname{TR} 37=I_{C X} \bar{E}_{H} /\left(q V_{M O D}\right)
\end{aligned}
$$

The test cell plasma volume is

$$
V_{M O D}=\pi r_{M O D}^{2} L_{m, e f f}
$$

where $r_{M O D}$ is the test cell plasma radius and

$$
L_{m, e f f}=\frac{B_{m 0}}{n_{H}^{2}} \int_{\text {test }} d z \frac{m_{H}^{2}(z)}{B(z)}
$$

is the test cell $n^{2}$-weighted effactive length. Typically, $\eta_{H}(z)$ is not available as a function of position and the effective length is taken to be $L_{m, e f f}=0.9 L_{\text {eff }}$ where $L_{\text {eff }}=B_{m 0} f d z / B(z)$. The radial average of the plasma density squared is given by

$$
\overline{n^{2}}=n_{0}^{2}\left\{\gamma^{2} /[(\gamma+1)(\gamma+2)]\right\}
$$


where $\gamma=4$ for a quartic profile. $\bar{E}_{\text {INJ }}$ is the average injection energy of the test cell neutral beam particles. The average loss energy for the HOT particles is obtajned from the Logan-Rensink model as

$$
\bar{E}_{L, H O T}=\bar{E}_{I N J} \frac{1.0+\left(E_{e} / \bar{E}_{I N J}\right)\left(\tau_{R}\right)}{1.0+\tau_{R}}
$$

where

$$
\tau_{R}=\frac{0.156}{\sqrt{A_{D T}}}\left(\frac{E_{I N J}}{T_{e c}}\right)^{3 / 2} \frac{\log _{10}\left(R_{e f f}\right)}{\ln \left(E_{I N J}-E_{L, H O T}\right)} \frac{\ln \Lambda_{e j}}{\ln \Lambda_{i i}}
$$

and

$$
\begin{aligned}
& E_{c}=\frac{\phi_{m 0}}{\left(R_{m} \sin ^{2} \theta_{I N J}-1.0\right)} \\
& R_{m}=\frac{B_{m m, V A C}}{B_{m 0, V A C}\left(1.0-B_{m 0}\right)^{1 / 2}}
\end{aligned}
$$

where $\theta_{1 \mathrm{NJ}}$ is the injection angle of the neutral beams and $A_{D T}=2.5$ amu. The effective mirror ratio in the test cell is

$$
R_{\text {eff }}=\frac{R_{m} \sin ^{2} \theta_{I N J}}{1.0+\phi_{m 0} / E_{\text {INJ }}}
$$

and

$$
\begin{aligned}
& \Lambda_{e i}=5.7 \times 10^{13} \mathrm{~T}_{\mathrm{ec}} / \sqrt{\mathrm{n}_{H}} \\
& \Lambda_{i j}=1.4 \times 10^{15}\left(\frac{\mathrm{T}_{\mathrm{ec}} \overline{E_{H}}}{n_{H}}\right)^{1 / 2}
\end{aligned}
$$


The confinement parameter for HOT particles in the test cell is given by

$$
(m)_{P C}=f_{P C}\left[\frac{1.0}{(n \tau)_{i i}}+\frac{1.0}{(n t)_{e i}}\right]^{-1}
$$

where the fast ion scattering time on the background ions is

$$
\left(n_{\tau}\right)_{i \mathrm{i}}=2.76 \times 10^{12} \sqrt{\bar{A}_{\mathrm{DT}}} \bar{E}_{\mathrm{INJ}}^{3 / 2} \log _{10}\left(R_{\mathrm{eff}}\right) / \ln \Lambda_{\mathrm{ij}}
$$

and the slowing down time on electrons is

$$
(m)_{e i}=1.0 \times 10^{13} A_{D T} T_{e C}^{3 / 2} \ln \left(\bar{E}_{I N J} / \bar{E}_{L, H O T}\right) / \ln \Lambda_{e i}
$$

The coefficient $f_{P C}$ is equal to 1.0 in the standard Logan-Rens ink plug model. However, this model was generated from Fokker-Planck results which assumed that the loss cone in velocity space was empty. For HOT particles in the test cell the loss cone is partially filled with HOT* and COLO particles so that the conf inement of the HOT's will be modified. Multi-region Fokker-P lanck $(7)$ results indicate that for typical MFTF- $\alpha+T$ parameters the confinement parameter predicted by Eq. (3.37) may be at least 50 \% low. In addition, the difference between the predictions of $E q$. (3.37) (with $f_{P C}=1.0$ ) and the recent Fokker-Planck results is sensitive to the plugging potential (relative to the COLD ion temperature), the test cell injection energy and the COLD ion density. Calibration of $E q$. (3.37) over a range of these parameters remains an important area of future work. The studies to date have used $f_{\mathrm{PC}}=1.5$.

The energy drag parameter for HOT's on electrons is

$$
(n T)_{\mathrm{He}}=1.0 \times 10^{13} \mathrm{~A}_{\mathrm{DT}} \mathrm{T}_{\mathrm{eC}}^{3 / 2} / 1 \mathrm{n} \mathrm{A}_{\mathrm{eH}}
$$

where

$$
\Lambda_{\mathrm{eH}}=2.65 \times 10^{13} \mathrm{~T}_{\mathrm{ec}} / \overline{\mathrm{n}_{\mathrm{H}}}
$$

and the drag parameter for HOT'S on COLD ions is

$$
\left(n_{T}\right)_{H C}=2.27 \times 10^{11} \sqrt{A_{D T}}\left(T_{C}+0.8 \overline{E_{H}}\right)^{3 / 2} / \ln \Lambda_{H C}
$$


where

$$
\Lambda_{H C}=\frac{3.08 \times 10^{14}\left(\frac{1}{2}\right)\left(T_{C}+0.8 \bar{E}_{H}\right)}{\left[2.0\left(\frac{n_{H}}{\bar{E}_{H}}+\frac{n_{C}}{T_{C}}\right)\right]^{1 / 2}}
$$

The energy given to the HOT's due to alphas from COLD-COLO and HOT*-HOT* fusion reactions slowing down in the test cell is given by

$$
E_{\alpha, H O T}^{C C} \equiv E_{\alpha, H O T}^{* *}=U_{D T, \alpha} F_{\alpha, H O T}
$$

where

$$
f_{\alpha, H O T}=\frac{f_{\alpha_{,} i m} n_{H}}{n_{H}+n_{H}^{*}+n_{c} \exp \left(-\phi_{m 0} / T_{c}\right)}
$$

and $f_{\alpha, i m}$ is the fraction of alpha energy given to ions in the test cell (see Sec. 5). For HOT-HOT fusion reactions the energy of the reacting ions must be subtracted to give

$$
E_{\alpha, H O T}^{H H}=U_{D T, \alpha} f_{\alpha, H O T}-\left(90+2.0 \overline{E_{H}}\right)
$$

Finally, Eq. (3.26) gives the energy lost from the HOT population oue to charge exchange events between beam particles and the plasma. The charge exchange models are described in Sec. 5.1.

\subsection{Wall Loading}

The neutron wall loading in the test cell region is given by

$$
\Gamma_{T C}=\frac{q}{T 000} V_{M O D} E_{n}(\operatorname{TR} 41+T R 42+T R 43) /\left(1.0 \times 10^{4} D_{V}\right)
$$

where

$$
\operatorname{TR41}=\frac{1}{4} \bar{n}_{H}^{2}\left\langle\sigma v\left(\bar{E}_{H}\right)\right\rangle_{H}
$$




$$
\begin{aligned}
& \text { TR42 }=\frac{1}{4} \overline{\left[n_{c} \exp \left(-\Phi_{m 0} / T_{c}\right)\right]^{2}}\left\langle\sigma v\left(T_{c}\right)\right\rangle \\
& T R 43=\frac{1}{4} \overline{\left(n_{H}^{*}\right)^{2}}\left\langle\sigma v\left(E_{H}\right)\right\rangle_{H} \\
& O_{V}=2 \pi r_{m, F W} L_{m, e f f} .
\end{aligned}
$$

and $E_{n}=14.1 \mathrm{MeV}$. The test cel1 first wal1 radius is

$$
r_{m, F W}=r_{m}+\frac{54}{B_{m 0, V A C}}
$$

i.e., two alpha Larmor radii larger than the radius of the plasma. The reaction rates, $\langle\sigma v\rangle_{H}$, for hot ions are described in Sec. 5.2 .

\subsection{HOT*Particle Balance}

The density of the HOT* particles in the central cell is obtained from a particle balance of the form

$$
\text { TR51 - TR53 - TR54 }=0
$$

where

$$
\begin{aligned}
& \text { TR51 }=c_{V X, H H S} \overline{n_{H} n_{e m}} v_{M O D} /\left(n_{\tau}\right)_{P C} \\
& T R 53=\overline{n_{\hat{H}}^{\tau} n_{e C}}\left(V_{C C}-V_{M O D}\right) /\left(n_{\tau}\right)_{P C C} \\
& T R 54=\overline{n_{H}^{\star} n_{e m}} V_{M O D} /(n \tau)_{P C C}
\end{aligned}
$$

The particle confinement parameter $\left(n_{T}\right)_{P C C}$ for the HOT* ions is calculated from a Logan-Rens ink model for the HOT*. The complete model is described in the next section. The coefficient $\mathrm{C}_{\mathrm{VX}}$, HHS gives the fraction of the HOT ions which 
cross the loss boundary in Fig. 2 into the HOT* population. It is calculated cons istent with the flow of particles across the other boundaries in velocity space in a separate model which is described in detail in Sec. 3.7. Typically $\mathrm{C}_{\mathrm{VX}, \mathrm{H}} \mathrm{HS}$ is in the range 0.3 to 0.5 .

\subsection{HOT* Average Energy}

The average energy of the HOT* population is obtained from a modified Logan-Rensink plug model similar to that used for the HOT particles. In this case, however, the relative potential is zero since the HOT*'s occupy the central cell and the injection energy and angle must be calculated to represent the particles which escape from the test cell into the HOT* class. The energy balance takes the form

$$
\begin{gathered}
\frac{\mathrm{q}}{1000}(\operatorname{TR} 6]-\operatorname{TR} 62-\operatorname{TR} 63-\operatorname{TR} 65-\operatorname{TR} 66+\operatorname{TR} 601 \\
+\mathrm{TR} 602+\operatorname{TR} 603+\operatorname{TR} 604)=0
\end{gathered}
$$

where

$$
\begin{aligned}
& \text { TR6 } 1=\left[\overline{\left[n_{H}^{\hbar} n_{e c}\right.}\left(v_{c c}-V_{M O D}\right)+\overline{n_{H}^{*} n_{e m}} v_{M 00}\right]\left[\overline{E_{I N}^{*}}\right]+\phi_{m 0} \\
& \text { - E[,HOT }] /(n \tau)_{P C C} \\
& \text { TR62 }=\overline{n_{H}^{\star} n_{e c}}\left(V_{c c}-V_{M O D}\right)\left(\overline{E_{H}^{\star}}-\frac{3}{2} T_{e c}\right) /\left(n_{\tau}\right)_{s e} \\
& \text { TR66 }=\overline{n_{H}^{\star} n_{e m}} V_{M O D}\left(\overline{E_{H}^{\star}}-\frac{3}{2} T_{e c}\right) /\left(n_{\tau}\right)_{\text {se }} \\
& \text { TR63 }=\overline{n_{H}^{t} n_{C}}\left(V_{c C}-V_{M O D}\right)\left(\overline{E_{H}^{\bar{t}}}-\frac{3}{2} T_{c}\right) /\left(n_{T}\right)_{S C}
\end{aligned}
$$




$$
\begin{aligned}
& \text { TR65 }=\overline{n_{H}^{*} n_{c} \exp \left(-\phi_{m 0} / T_{c}\right)} V_{M 00}\left(\overline{E_{H}^{E}}-\frac{3}{2} T_{c}\right) /\left(n_{\tau}\right)_{S C} \\
& T R 601=\frac{1}{4} \bar{n}_{C}^{2}\left\langle\sigma v\left(T_{C}\right)\right\rangle E_{\alpha, *}^{c c}\left(V_{C C}-V_{M O D}\right) \\
& \operatorname{TR602}=\frac{1}{4} \overline{\left[n_{c} \exp \left(-\phi_{m 0} / T_{c}\right)\right]^{2}}\left\langle\sigma v\left(T_{c}\right)\right\rangle E_{\alpha_{s} *}^{c m} V_{M 0 D} \\
& T R 603=\frac{1}{4} \overline{\left(n_{H}^{*}\right)^{2}}\left\langle\sigma V_{2}\left(E_{H}\right\rangle_{H} E_{\alpha, *}^{* *} V_{C C}\right. \\
& \operatorname{TR604}=\frac{1}{4} \overline{\left(n_{H}\right)^{2}}\left\langle\sigma v\left(\overline{E_{H}}\right)\right\rangle_{H} E_{\alpha, *}^{H H} V_{M O D}
\end{aligned}
$$

The average loss energy for the HOT*'s is calculated from a Logan-Rensink model as

$$
{\overline{E_{L, H O T}^{\star}}}=\frac{\overline{E_{I N J J}^{\star}}}{\left(1.0+\tau_{R}^{\star}\right)}
$$

where

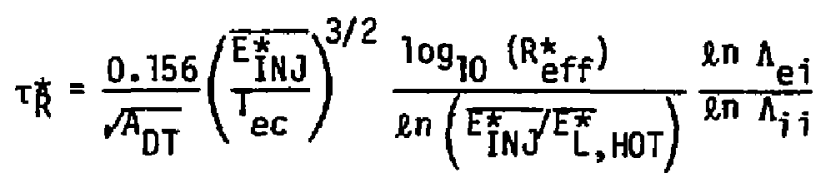

$$
\begin{aligned}
& R_{e f f}^{*}=R_{m}^{*} \sin ^{2} \theta_{I N J}^{*} \\
& R_{m}^{*}=\frac{{ }_{C H O K E}}{B_{C, Y a c} \sqrt{T-\beta_{C}}}
\end{aligned}
$$




$$
\theta_{I N J}=\arcsin \left[\left(\frac{B_{c, v a c} \sqrt{1}-\overline{B_{c}}}{B_{m m, v a c}}\right)^{1 / 2}\right]
$$

The injection angle given by Eq. (3.71) is precisely the angle at which particles would be injected into the central cell (at the minimum field) so that their turning points would be at the location of the peak test cell field. In this way the Logan-Rensink model for the HOT* uses the particles which are lost from the test cell as the beam source. The average beam energy is given by

$$
\overline{E_{\text {INJ }}^{E}}=\left(\overline{E_{L, H O T}^{*}}-\frac{3}{2} T_{C} C_{V X, H C}\right) / C_{V X, H H S}
$$

where $C_{V X, H C}=1.0-C_{V X, H H S}$ is the fraction of HOT particles crossing the boundary into the COLD population (Sec. 3.7).

The confinement parameters are calculated as

$$
(n \tau)_{P C C}=f_{P C C}\left[\frac{1.0}{(n \tau)_{i j}^{*}}+\frac{1.0}{(n \tau)_{e j}^{\star}}\right]^{-1}
$$

where

$$
\begin{aligned}
& \left(n_{T}\right)_{i j}^{\star}=2.76 \times 10^{12} \sqrt{A_{D T}} \overline{E_{I N J}^{*}} 3 / 2 \log _{10}\left(R_{e f f}^{*}\right) / \ell n \Lambda_{i i}^{*} \\
& \left(n_{\tau}\right)_{e i}^{\star}=3.0 \times 10^{13} A_{D T} T_{e C}^{3 / 2} \ln \left(\overline{E_{I N J}^{*}} / \overline{E_{L}^{*}}, H_{O T}\right) / \ln \Lambda_{e i}^{*}
\end{aligned}
$$

and

$$
\begin{aligned}
& \Lambda_{i j}^{*}=1.4 \times 10^{15}\left(\frac{\mathrm{ec}^{\top} \mathrm{c}}{\bar{n}_{\mathrm{c}}}\right)^{1 / 2} \\
& \Lambda_{\mathrm{e} i}^{\star}=5.7 \times 10^{13} \mathrm{~T}_{\mathrm{ec}} / \sqrt{\mathrm{n}_{\mathrm{c}}}
\end{aligned}
$$


Multi-region Fokker-Planck results do not give a direct calibration of $f_{P C C}$ Typically $f_{P C C}$ has been taken equal to $f_{P C}$ in the studies so far (Sec. 3.3). The energy conf inement parameters are

$$
\begin{aligned}
& (n T)_{S e}=1.0 \times 10^{13} A_{D T} T_{e C}^{3 / 2 / l n} \Lambda_{e s} \\
& \left(n_{T}\right)_{S C}=2.27 \times 10^{11} \sqrt{A_{D T}}\left(T_{C}+0.8 \overline{E_{H}^{J}}\right)^{3 / 2} / 2 n \Lambda_{S C}
\end{aligned}
$$

where

$$
\begin{aligned}
& \Lambda_{\mathrm{es}}=2.65 \times 10^{13} \mathrm{~T}_{\mathrm{ec}} / \overline{n_{\mathrm{H}}^{\bar{\epsilon}}}
\end{aligned}
$$

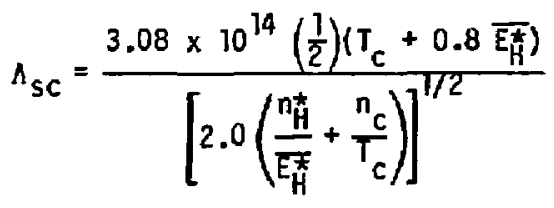

Finally the alpha energy coefficients are given by

$$
\begin{aligned}
& E_{\alpha, *}^{C C}=U_{D T, \alpha} f_{\alpha, *} \\
& E_{\alpha, *}^{C m}=E_{\alpha, *}^{H H}=U_{D T, \alpha} f_{\alpha, *}^{m}
\end{aligned}
$$

and

$$
E_{\alpha, \star}^{\star \star *}=U_{0 T, \alpha} f_{\alpha, *}-\left(90+2 \overline{E_{H}^{\bar{\hbar}}}\right)
$$

where the coefficients $f_{\alpha, *}$ and $f_{\alpha, *}^{m}$ give the fraction of alpha energy transferred to the HOT*'s in the central cell and test cell, respectively.

$$
f_{\alpha, *}^{m}=\frac{f_{\alpha, i m} n_{H}^{k}}{n_{H}+n_{H}^{k}+n_{c} \exp \left(-\phi_{m 0^{\prime}}{ }^{\top}\right)}
$$




$$
\dot{f}_{\alpha, *}=\frac{f_{\alpha, j m} n_{H}^{*}}{n_{H}^{t}+n_{c}}
$$

and $f_{\alpha, i m}$ is described in Sec. 5.3.

\subsection{Convection Model}

Particles which cross the velocity space boundaries in Fig. 2 may enter the new distribution at an energy higher than the average energy of that distribution. In this way energy may be convected from one population to another. To account for this, the net particle flow rates across the velocity space boundaries must be calculated. These rates depend on the details of the gradients in the diștribution function at the boundaries, which are not yet available from the multi-ragion Fokker-P lanck studies. Models of the fractions of particles flowing from each hot distribution across the bounaaries into adjacent regions of velocity space are described below. When the flow rates are available from the Fokker-P lanck studies they can be used to calibrate the models.

The fractions of HOT particles crossing the boundary into the HOT* and COLD trapped distributions are calculated by assuming that the HOT distribution is near ly Maxwellian centered about the injection point with average energy $\bar{E}_{H}$ and density $n_{H}$. Contours of the distribution function from the Fokker-planck results show that this is a good approximation. From this assumption the number density of particles on the boundary is calculated. The Fokker-Planck results also show that the slope of the distribution does not change dramatically along the boundary. The relative fractions of particles crossing into the COLD and HOT* populations at any point on the boundary are taken to be proportional to the density of particles at that point. Integrating over the boundary gives the fraction of the tota] loss from the HOT to HOT* and from the HOT to COLD distributions as

$$
c_{V X, H H S}=1.0-C_{V X, H C}
$$




$$
c_{V X, H C}=\frac{2.0-\operatorname{erfc}\left(X_{1 H}\right)-\operatorname{erfc}\left(X_{2 H}\right)}{2.0-\operatorname{erfc}\left(X_{1 H}\right)}
$$

where

$$
\begin{aligned}
& x_{1 H}=\left(\frac{3 \overline{E_{1 N J}}}{2 \overline{E_{H}}}\right)^{1 / 2} \cos \left(\theta_{H}-\theta_{I N J}\right) \\
& x_{2 H}=\left(\frac{3 \phi_{C}}{2 E_{H}}\right)^{1 / 2}-\left(\frac{3 \overline{E_{I N J}}}{2 \overline{E_{H}}}\right)^{1 / 2} \cos \left(\theta_{H}-\theta_{I N J}\right) \\
& \theta_{H}=\arcsin \left(\frac{B_{m 0, V A C} \sqrt{1-\Phi_{m D}}}{B_{m m, V A C}}\right)^{1 / 2}
\end{aligned}
$$

and $\operatorname{erfc}(x)$ is the complementary error function.

Though these assumptions may not be as appropriate for the losses from the HOT* population, because the slope of the distribution is very different on the boundary with the COLD region compared with the boundary of the loss cone, they have been used at this time. The flow from the HOT* distribution should be a second order effect on the performance of the test cell compared with the losses from the HOT's so that the error made by us ing this model should be small. The fraction of HOT*'s flowing in to the COLO population is taken to be

$$
c_{\mathrm{VX}, \mathrm{HSC}}=\frac{2.0-\operatorname{erfc}\left(\mathrm{X}_{\mathrm{HSS}}\right)-\operatorname{erfc}\left(\mathrm{X}_{2 \mathrm{HS}}\right)}{2.0-\operatorname{erfc}\left(X_{\mathrm{HS}}\right)}
$$

where

$$
x_{1 H S}=\left(\frac{3 \overline{E_{I N J}^{\star}}}{2 E_{H}^{t}}\right)^{1 / 2} \cos \left(\theta^{*}-\theta_{I N J}^{*}\right)
$$




$$
\begin{aligned}
& x_{2 H S}=\left(\frac{3 \phi_{c}}{2 \overline{E_{H}}}\right)^{1 / 2}-\left(\frac{3 \overline{E_{I N J}^{ \pm}}}{2 \overline{E_{H}^{E}}}\right)^{1 / 2} \cos \left(\theta^{*}-\theta_{\text {INJ }}^{\star}\right) \\
& \theta^{*}=\arcsin \left(\frac{{ }_{C}{ }_{C, V A C} \sqrt{1-B_{C}}}{{ }_{C H O K E}}\right)^{1 / 2}
\end{aligned}
$$

The fraction flowing into the loss cone is $C_{V X, H S L}=1.0-C_{V X, H S C}$.

$F$ inally, note that the Fokker-P lanck velocity space model does not distinguish between HOT* and COLD trapped particles in the central cell. Ins tead there are just three classes of particles, HOT mirror trapped in the test cell, WARM mirror trapped in the central cell, and COLO passing particles which are electrostatically trapped and exist in the entire device. The somewhat artificial distinctions made in the TMRBAR models are necessitated by the passing density formulas which map the density of passing ions in each region of the end cell from a Maxwellian distribution in the central cell.

\subsection{Plasma and First Wall Radii}

The plasma $r$ adius in the test cell is calculated by mapping the plasma flux bundle from the central cell as

$$
r_{M O D}=r_{c}\left[\frac{{ }^{B} C, V A C\left(1-\overline{B_{c}}\right)^{1 / 2}}{B_{m 0, V A C}\left(1-\overline{B_{m 0}}\right)}\right]^{1 / 2}
$$

where

$$
\begin{aligned}
& \overline{\beta_{c}}=\beta_{c} \gamma /(\gamma+2) \\
& \overline{\beta_{m 0}}=\beta_{m 0} \gamma /(\gamma+2)
\end{aligned}
$$


and $Y=4$ for a quartic radial profile. The test cell first wall is taken to be two alpha Larmor radii from the edge of the plasma so that the first wall radius is

$$
r_{M O D, F W}=r_{M O D}+\frac{54}{B_{m 0, V A C}}
$$

\section{CENTRAL CELL AND END CELL EQUATIONS}

Operation of a beam driven test celi in the central cell of a tandem mirror device changes the plasma physics parameters in the entire machine. While the trends in test cell performance can be predicted to a certain extent based on simple argul. ents (wall loading at fixed beta and test cel1 confinement is proportional to trapped beam current etc.), the aspects of the tandert mirror physics which most often limit the achievable performance of a particular configuration concern the central cell particle and energy balances and the special end cell physics constraints. When the test celi is to be inserted into a particular device as an upgrade, the maximum capabilities of the end cell systems can be the dominating factor 1 imiting the achievable test cell performance. For these reasons, modeling of the effects of test cell operation on the remainder of the device has been done in parallel with the test cell modeling.

The changes in the physics models of the central cell and end cells which are required when a test cell is operated in the device are described below. Rather than present all of the models for these regions only those which require changes to take into account test cell effects are given. The complete description of the original TMRBAR models is given in Ref. 1 with recent improvements to be presented in a separate report. (2) Parameters which are not explicitly described in this report may be assumed to be of the form given in Ref. 1 .

\subsection{Global Charge Neutrality}

Global charge balance is achieved in the models by setting the net loss rates of ions and electrons from the device equal. Steady state is achieved 
by specifying a neutral particle source rate equal to the loss rate. When a test cell is operated in the device part of the trapped beam current in the test cell contributes to fuel the COLD population in the remainder of the device. The charge balance equation used to obta in $\phi_{\mathrm{e}}$ takes the form

$$
I_{B L R N}+I_{\text {TRAN } 1}+J_{N B}+I_{D T, \text { nEO }}+I_{B L R N H}-I_{\text {TRAN2 }}=0
$$

The ion burn-up term contain ing test cell effects is

$$
\begin{aligned}
I_{B L R N H}= & \frac{q}{\pi 000} v_{c c} \frac{1}{2}\left[\overline{n_{H}^{2}}\left\langle\sigma v\left(\overline{E_{H}}\right)\right\rangle_{H} v_{M O D} / v_{c c}\right. \\
& +\overline{\left(n_{H}^{*}\right)^{2}}\left\langle\sigma v\left(\overline{E_{H}}\right)_{H}\right]
\end{aligned}
$$

Ion and electron particle losses from the device are given by $\mathrm{I}_{\text {TRAN } 1}$ and I TRAN2, respectively. For ions

$$
I_{\text {TRAN } 1}=\frac{q}{1000}[\text { TPTR } 3+\text { TPTR2 }+ \text { TPTR3 + TPTR4 }]
$$

where

$$
\begin{aligned}
& \text { TPTR } 1=\overline{n_{c} n_{e c}}\left(v_{c c}-M_{M O D}\right) /\left(n_{T}\right)_{C I} \\
& \text { TPTR2 }=\overline{n_{c} \exp \left(-\phi_{\mathrm{mO}} / T_{c}\right) n_{e m}} v_{M O d} /\left(n_{\tau}\right)_{C I} \\
& \text { TPTR3 }=\overline{n_{H}^{*} n_{e C}}\left(V_{c c}-V_{M O D}\right) C_{V X, H S L} /\left(n_{T}\right)_{e}^{*} i \\
& +\overline{n_{H} n_{e c}}\left(v_{c c}-v_{M O D}\right) /\left(n_{\tau}\right)_{i j}^{*} \\
& \text { TPTR4 }=\overline{n_{\mathrm{H}}^{\star} n_{\mathrm{em}}} V_{\text {HOD }} c_{\mathrm{VX}, \mathrm{HSL}} /\left(m_{T}\right)_{\mathrm{e} i}^{\star}+\overline{n_{\mathrm{H}}^{\star} n_{\mathrm{em}}} V_{M O D} /\left(n_{\tau}\right)_{\mathrm{i} i}^{\star}
\end{aligned}
$$


The coefficient $C_{V X, H S L}=1.0-C_{V X,{ }_{S C C}}[$ see Eq. (3.92)]. The confinement parameters $\left(n_{\tau}\right)_{j i}^{\star}$ and $\left(n_{\tau}\right)_{e j}^{*}$ are givis in Eqs. (3.74) and

(3.75), respectively. The parameter $(m)_{C I}$ is the total particle confinement for COLD jons defined as

$$
(n \tau)_{C I}=\left[\frac{1.0}{(n \tau)_{C R}}+\frac{1.0}{(n \tau)_{C A}}\right]^{-1}
$$

where $(n \tau)_{C R}$ and $(n \tau)_{C A}$ are the radial (drift pump in the transition) ana axial (Pastukhov) confinement parameters. The electron term is

$$
I_{\text {TRAN2 }}=\frac{q}{1000}\left[\overline{n_{e c}^{2}}\left(v_{c C}-v_{M O D}\right) /(n \tau)_{c e}+\overline{n_{e m}^{2}} v_{M O D} /(n \tau)_{c e m}\right]
$$

where $\left(n_{\tau}\right)_{c e}$ is the axial (Pastukhov) confinement parameter for central cell electrons and $(\boldsymbol{m})$ cem the corresponding parameter for electrons in the test cell given by

$$
(n)_{c e m}=(n \tau)_{c e}\left[\frac{\phi_{e}+\phi_{m 0}}{\phi_{e}}\right] \exp \left[\phi_{m 0} / T_{e c}\right]
$$

The rethaining terms in Eq. (4.1) are unchanged from Ref. 1.

\subsection{Electron Power Balance}

The electron power balance changes dramatically when a test cell is added in a tandeni mirror device. Orag of the hot ion components on the Maxwellian electron background typically produces the dominant power sources for the electrons. The power balance equation becomes

$$
\begin{aligned}
P_{E C H A}+P_{e i}+P_{e, S L O S H}+P_{e, A N C}+P_{e, F U S}-P_{e, T R A N} \\
+P_{E C H B}-P_{\text {BREM }}=0
\end{aligned}
$$

Iwo of the terms in F.q. (4.11) contain changes which are independent of the test cell modeling. The power transferred to the central cell electrons from ECRH heating at the barrier point $P_{E C H B}$ is now taken to be on iy the orag power from hot electron drag on cold passing electrons. The 
bremstrahlung power radiated from the electron plasma is given by

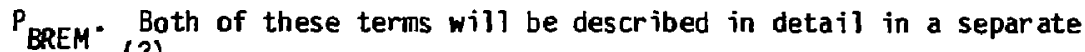
report. (2)

The dominant term in Eq. (4.11) for test ce11 configurations is the electron ion drag term $P_{e i}$. The equation is

$$
P_{\text {ei }}=\frac{q}{1000}[\text { TEEIO + TEEI } 1+\text { TEEI }+ \text { TEE } 13+\text { TEEI } 4]
$$

where

$$
\begin{aligned}
& \text { TEEIO }=\overline{n_{c} n_{e c}} V_{c c}\left(\frac{3}{2} T_{c}-\frac{3}{2} T_{e c} / /\left(n_{\tau}\right)_{e i}\right. \\
& \text { TEEI l }=\overline{n_{H} n_{e F}} V_{M O D}\left(\overline{E_{H}}-\frac{3}{2} T_{e c}\right) /(n \tau)_{H e} \\
& \text { TEEI2 }=\overline{n_{c} c_{\alpha} n_{e c}} V_{c c}\left(\frac{3}{2} T_{\alpha, A V G}-\frac{3}{2} T_{e c}\right) 2.5 /\left(n_{\tau}\right)_{e i} \\
& \text { TEEI3 }=\overline{n_{H}^{\hbar} n_{e c}}\left(V_{c c}-V_{M O D}\right)\left(\overline{E_{H}^{E}}-\frac{3}{2} T_{e c}\right) /\left(n_{\tau}\right)_{e i} \\
& \text { TEE I4 }=\overline{n_{H}^{\star} n_{\text {em }}} V_{M O D}\left(\overline{E_{H}^{\star}}-\frac{3}{2} T_{e c}\right) /\left(n_{\tau}\right)_{e i}
\end{aligned}
$$

Equations (4.13) to (4.17) describe COLD ion drag on electrons in the central ce 1\}, HOT jon drag on electrons in the test ce11, warm alpha drag on electrons in the central cell, and HOT* ion drag on electrons in the central cell, respectively. The confinement parameter $\left(\mathrm{n}_{\mathrm{T}}\right)_{\mathrm{He}}$ is defined in Eq. (3.40). The term ( $\mathrm{nt})_{\mathrm{e} i}$ is the electron ion drag parameter for the central cell. Strictly speaking, Eqs. (4.73) and (4.15) should be broken into two terms each to take into account effects of the potential $\phi_{m 0}$ in the test cel3. This will be cone in a future upgrade of the code.

The term describing energy given to electrons from fusion alpha slowing down takes the form 


$$
P_{\text {E,FUS }}=\frac{q}{1000}[P F 1+P F 2+P F 3]
$$

where

$$
\begin{aligned}
& \text { PF1 }=\frac{1}{4} \overline{n_{c}^{2}}\left\langle\sigma v\left(T_{c}\right)\right\rangle U_{D T, \alpha} f_{\alpha, e} v_{c c} \\
& P F 2=\frac{1}{4} \overline{n_{H}^{2}}\left\langle\sigma v\left(E_{H}\right)\right\rangle_{H} U_{D T, \alpha} f_{\alpha, e m} v_{M O D} \\
& P F 3=\frac{1}{4} \overline{\left.\left(n_{H}\right)\right)^{2}}\left\langle\sigma V\left(E_{H}\right)\right\rangle_{H} U_{D T, \alpha} f_{\alpha, e} v_{c c}
\end{aligned}
$$

The terms due to HOT-HOT fusions and HOT*-HOT* fusions are given in Eqs. (4.20) ano (4.21), respectively. The fractions of hot alpha energy given to electrons in the central cell and test cell, $f_{\alpha, e}$ and $f_{\alpha, e n l}$ respectively, are described in Sec. 5.3.

Finally the power lost when electrons are lost from the device takes the form

$$
\left.P_{\text {e,TRAN }}=\frac{9}{1000}[\text { TEETR }]+\text { TEETR2 }\right]
$$

where

$$
\begin{aligned}
& \text { TEETR } 1=\overline{n_{e c}^{2}}\left(v_{c c}-v_{M O D}\right)\left(\phi_{e}+T_{e c}\right) /(n \tau) \\
& \text { TEETR2 }=\overline{n_{e m}^{2}} Y_{M O D}\left(\phi_{e}+\phi_{m O}+T_{e c}\right) /(n \tau)_{c e m}
\end{aligned}
$$

and the confinement parameter $\left(n_{T}\right)_{\text {cem }}$ is given in $\mathrm{Eq} .(4.10)$.

\subsection{Ion Power Ba lance}

This section describes the power balance for the COLD Maxwellian ions in the central cell. The power balances for the hot ions in the central cell and 
test cell regions are described in Secs. 3.6 and 3.3, respectively. When a test cell is operated in the device the colD ion power balance includes source terms describing energy transfer between the hot populations and the COLD ions as well as power convected into the iraxwellian distribution by particles crossing the boundaries in velacity space with energy above the COLD ion temper ature.

The power balance equation takes the form

$$
P_{B L R N}+P_{\text {ICRH }}+P_{i j}+P_{H S}+P_{H C}-P_{n \in O}-P_{A X}-P_{i e}-P_{R A D}=0
$$

Typically the dominant source terms are the hot ion-cold ion energy transfer term $P_{i j}$ and the convection terms $P_{H S}$ and $P_{H C}$ from the HOT* and HOT populations, respectively. The energy transfer term takes the form

$$
P_{i j}=\frac{G}{1000}[T G 1+T G 2+T G 3]
$$

where

$$
\begin{aligned}
& T G 1=\overline{n_{H} n_{C}} \exp \left(-\phi_{m 0} / T_{C}\right) V_{M O D}\left(\overline{E_{H}}-\frac{3}{2} T_{C}\right) /\left(n_{\tau}\right)_{H C} \\
& T G 2=\overline{n_{H}^{\star} n_{C}}\left(V_{C C}-V_{M O D}\right)\left(\overline{E_{H}^{\star}}-\frac{3}{2} T_{C}\right) /\left(n_{\tau}\right)_{S C} \\
& T G 3=\overline{n_{H}^{\star} n_{C}} V_{M O D}\left(\overline{E_{H}^{\star}}-\frac{3}{2} T_{C}\right) /\left(n_{\tau}\right)_{S C}
\end{aligned}
$$

The confinement parameters $\left(n_{T}\right)_{H C}$ and $\left(n_{\tau}\right)_{S C}$ are given by EqS. (3.42) and (3.79), respectively. The power source due to convection from the HOT population is

$$
P_{H C}=\frac{q}{1000} \overline{n_{H} n_{e m}} V_{H O D} c_{V X, H C}\left(\frac{3}{2} T_{C}\right) /\left(n_{T}\right)_{P C}
$$

where $\left(n_{T}\right)_{P C}$ is defined in Eq. (3.37), and the fraction of HOT particles flowing in to the HOT* population is defined in Eq. (3.87). This model assumes that the HOT particles crossing the boundary into the COLD region carry an average energy of $3 / 2 \mathrm{~T}_{\mathrm{c}}$. 
Another model is ayailable which assumes that the HOT particles carry an average energy of $\phi_{c}$ into the HOT* $d$ istribution to follow changes in the artificial boundary between the HOT*'s and COLO's with $\Phi_{C^{*}}$. In this case Eq. (4.30) is replaced by

$$
P_{H C}=\frac{q}{1000} \overline{n_{H} n_{e m}} V_{M O D}\left(\overline{E_{L, H O T}}-\Phi_{C} c_{V X, H H S}\right) /(n T)_{P C}
$$

where the average loss energy of the HOT's is given by $\mathrm{Eq} .(3.30)$. To conserve the total energy flowing out of the HOT population the average injection energy for the HOT* class must be modified when Eq. (4.31) is used. In th is model Eq. (3.72) is replaced by

$$
\overline{E_{\text {INJ }}}=\phi_{C}
$$

F inally, the power source to the COLD population from convection of HOT* particles is given by

$$
\begin{aligned}
P_{H S}= & \frac{g}{0000}\left[\overline{n_{H}^{*} n_{e c}}\left(V_{C C}-V_{M O D}\right) c_{V X, H S C} /\left(n_{\tau}\right)_{e j}^{*}\right. \\
& \left.+\overline{n_{H}^{\star} n_{e m}} v_{M O D} C_{V X, H S C} /\left(n_{T}\right)_{e i}^{*}\right] \frac{3}{2} T_{C}
\end{aligned}
$$

where the confinement parameter $\left(n_{T}\right)_{e j}^{\star}$ is given in Eq. (3.75).

The other terms in Eq. (4.25) which include test cell effects are the hot alpha heating term $P_{B U R N}$, the radial loss term $P_{R A D}$, and the axial loss term $P_{A X}$. The heating of the COLO population by fusion alphas produced in HOT-HOT and HOT*-HOT* reactions is given by

$$
P_{\text {BURN }}=\frac{q}{1000}[T B 0+T B 1+T B 2]
$$

where

$$
T B 0=\frac{1}{4} \overline{n_{c}^{2}}\left\langle\sigma v\left(T_{c}\right)\right\rangle E_{\alpha} v_{c c}
$$




$$
\begin{aligned}
& T B 1=\frac{1}{4} \overline{n_{H}^{2}}\left\langle\sigma V\left(E_{H}\right)\right\rangle_{H} V_{D T, \alpha} f_{\alpha, C O L D}^{m} V_{M O D} \\
& T B 2=\frac{1}{4} \overline{\left(n_{H}\right)^{2}}\left\langle\sigma V\left(E_{F}\right)\right\rangle_{H} U_{D T, \alpha} f_{\alpha, C O L D} V_{C C}
\end{aligned}
$$

and

$$
E_{\alpha}=y_{D T, \alpha} f_{\alpha, i}-\left(90+3 T_{c}\right)
$$

Expressions for the fractions of alpha energy going to COLD ions in the central cell and test cell $f_{a, j}, f_{\alpha, \text { COLD }}$ will be presented in

Sec. 5.3. Strictly speak ing the contributions from Eqs. (4.35) and (4.37)

should be broken inco two parts, one from the test cell and the other from the remainder of the central cell, taking into account both the test cell potential and the changes in the alpha energy fractions. These effects will be included in the next upgrade of the code model.

The radial power loss due drift pumping of cold trapped ions in the transition region is

$$
P_{R A D}=\frac{G}{1000}[P C R]+P[R 2] f_{E L} T_{C}
$$

where

$$
\begin{aligned}
& P C R 1=\overline{n_{c} n_{e c}}\left(v_{c C}-\gamma_{M O D}\right) /(n T)_{C R} \\
& P C R 2=\overline{n_{C} \exp \left(-\phi_{C D D} / T_{c}\right) n_{e m}} v_{M O D} /(n \tau)_{C R}
\end{aligned}
$$

The product $f_{E L} T_{c}$ gives the average energy of the particles which are pumped out of the transition region. The coefficient $f_{E L}$ is an empirica 7 parameter taken to be 2.3 for most of the studies so far. The effect of the. test cell on the calculation of the radial confinement parameter $\langle n \tau\rangle_{\mathrm{CR}}$ is presented in Sec. 4.4. 
Finally, the axial power loss from the coLD ions is given by

$$
P_{A X}=\frac{q}{7000}[P C A 1+P C A 2]\left(\phi_{C}+T_{C}\right)
$$

where

$$
\begin{aligned}
& P C A T=\overline{n_{c} n_{e c}}\left(V_{c c}-V_{M J D}\right) /(m \tau)_{C A} \\
& P C A 2=\overline{n_{c} \exp \left(-\phi_{m 0} / T_{c}\right) n_{e m}} V_{M O D} /\left(n_{T}\right)_{C A}
\end{aligned}
$$

In this case the particles which can escape beyond the potential peak have energy equal to $\phi_{c}+T_{c}$.

\subsection{Radial Conf inement Parameter}

The original formulation of the radial confinement parameter (nt) $C R$ in TMRBAR is not easily acaptable to test cell configurations. Instead, $\left(m_{\mathrm{C}}\right)_{\mathrm{CR}}$ has been defined directly in terms of the trapping current of COLD ions in the transition region. The assumption is made that the trapping current calculated from the Futch-l.odestro formula ${ }^{(8)}$ is equal to the current which is pumped out by the drift pump coils so that the radial confinement parameter is

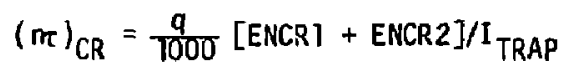

where

$$
\begin{aligned}
& \text { ENCR }]=\overline{n_{c} n_{e c}}\left(V_{c c}-V_{M O D}\right) \\
& E N C R 2=\overline{n_{c} n_{e m}} \exp \left(-\phi_{m 0} / T_{c}\right) V_{M O D}
\end{aligned}
$$

and I TRAP is the net trapping current of COLD ions in the transition. This definition is consistent with the radial and axial power loss terms Eq. (4.39) and (4.42). 


\subsection{Central Cell Density}

The central celi density is calculated from the equation for centra? cell beta. The allowable central cell beta input to the model depends on the test cell beta and the relative lengths of the test cell and central cell. The MHO stability calculations for the studies performed so far $(3,4)$ show that differences in these relative lengths can have a dramatic impact on the beta limits. In general, since the total MHD drive in the central cell region which can be stabilized by the end cells is a pressure weighted norma curvature, bad curvature regions in the test cell require that as test cell $\beta$ increases, central cell $\beta$ decreases. For each calculation the $B$ values are fixed at a point wilch is MHD stable and the central cell density is calculated from

$$
n_{c}=\left[\tilde{\beta}_{c} \frac{B_{C, V R C}^{2}}{2 \mu_{0}}-\left(P_{1}+P_{2}\right)\right] / T_{S U M}
$$

where

$$
\begin{aligned}
& P_{1}=0.667 n_{H}^{*} \overline{E_{H}^{\star}}+n_{H}^{*} T_{e c} \\
& P_{2}=8.3 \times 10^{10}\left\langle\sigma v\left(\overline{E_{H}^{*}}\right)\right\rangle_{H} T_{e c}^{3 / 2} U_{O T, \alpha} f_{\alpha, e} \frac{\left(n_{H}^{*}\right)^{2}}{n_{e c}} \\
& T_{S L M}=T_{C}+8.3 \times 10^{10}\left\langle\sigma V\left(T_{c}\right)\right\rangle T_{e c}^{3 / 2} U_{D T, \alpha} f_{\alpha e} \\
& \quad+T_{\alpha, A V G} C_{\alpha}+\left(1.0+2.0 C_{\alpha}\right) T_{e c}
\end{aligned}
$$

Equation (4.49) gives the central cell pressure due to HOT* ions and Eq. (4.50) gives the added central cell hot alpha pressure due to HOT*-HOT* fusion reactions. Equation (4.51) includes COLD ions, hot alphas due to COLD-COLD fusion reactions, warm alphas, and electrons. The average alpha temperature is given by Eq. (3.13), $U_{D T, \alpha}=3.52 \times 10^{3} \mathrm{keV}$ and $f_{\alpha, e}$ is described in Sec. 5.3 . 


\subsection{Alpha Particle Balance}

The total current of alpha particles produced in fusion reactions, which must be removed by the drift pump system to achieve steady state, is given by

$$
I_{\alpha, \text { TOT }}=\frac{q}{3000}\left[I_{C 1}+I_{C 2}+I_{C 3}+I_{C 4}\right]-I_{\alpha, \text { neo }}
$$

where

$$
\begin{aligned}
& I_{C 1}=\frac{1}{4} \overline{n_{C}^{2}}\left\langle\sigma v\left(T_{C}\right)\right\rangle\left(v_{C C}-V_{M O D}\right\rangle f_{P A R T} \\
& I_{C 2}=\frac{1}{4} \overline{\left[n_{C} \exp \left(-\phi_{m 0} / T_{C}\right)\right]^{2}}\left\langle\sigma V\left(T_{c}\right)\right\rangle V_{M O D} f_{P A R T}^{m} \\
& I_{C 3}=\frac{1}{4} \overline{\left(n_{H}\right)^{2}}\left\langle\sigma v\left(E_{H}\right)\right\rangle_{H} V_{M O D} f_{P A R T}^{m} \\
& I_{C 4}=\frac{1}{4} \overline{\left(n_{H}^{*}\right)^{2}}\left\langle\sigma V\left(E_{H}\right)\right\rangle_{H} V_{C C} f_{P A R T}
\end{aligned}
$$

The fractions of alpha particles remaining in the core plasma in the test cell and centrat cell, $f_{\text {PART }}^{m}$ and $f_{\text {PART }}$ respectively, are described in Sec. 5.3. Setting Eq. (4.52) equal to the Futch-Lodestro formula for the trapping current of alphas in the transition yields an equation which is solved for $g_{\alpha}$ in the transition, where for species $k$

$$
g_{k}=\frac{n_{\text {PASS }, k}+n_{\text {TRAP, } k}}{n_{\text {PASS, } k}}
$$

Note that the alphas in the transition are assumed to be at the COLD ion temperature $T_{c}$ rather than $T_{\alpha, A V G}$ since they do not interact with hot ions in the end cells. 


\subsection{Cold Fueling by Test Cell Beams}

The original TMRBAR models include specificaton of a COLD fueling current. This is the net input current to the COLD population in the central cell to balance particle losses. In test cell configurations the neutral beam current trapped in the test cell plasma is large and some of these particles scatter and drag in such a way that they qualify as a source to the COLD distribution. The fuel ing current calculated by the model becomes

$$
I_{\text {FUEL }}=I_{\text {FUEL } 1}+I_{\text {FUEL 2 }}+I_{\text {FUEL } 3}-I_{\text {FUEL } 4}
$$

where

$$
\begin{aligned}
& I_{\text {FUEL I }}=\frac{g}{T O O O O}\left(\frac{1}{2}\right) \bar{n}_{c}^{2}\left\langle\sigma v\left(T_{c}\right)\right\rangle v_{c c}
\end{aligned}
$$

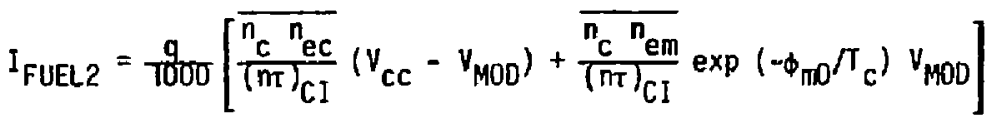

$$
\begin{aligned}
& I_{\text {FUEL } 3}=I_{D T, \text { neo }} \\
& I_{\text {FUEL4 }}=\frac{\mathrm{g}}{\operatorname{TOO}\left[\overline{n_{H} n_{e m}}\right.} c_{V X, H C} V_{M O O} /(n \tau)_{P C} \\
& +\overline{n_{H}^{\star} n_{e c}} c_{v X, H S C}\left(v_{c c}-v_{M O D}\right) /\left(n_{\tau}\right)_{e i}^{*} \\
& \left.+\overline{n_{\mathrm{H}}^{\star} n_{\mathrm{em}}} C_{\mathrm{VX}, \mathrm{HSC}} V_{\mathrm{MOO}} /\left(n_{\tau}\right)_{\mathrm{e} i}^{\star}\right]
\end{aligned}
$$

The calculation of the neoclassical loss current in $\mathrm{Eq} .(4.61)$ is not affected by the test $c \in 11$ and is described in detail in Ref. 1. Note that Eq. (4.58) can yield either a positive or negative COLD fueling current requirement. Positive $I_{F U E L}$ indicates that a supplementary fueling system (pellet injector, low energy neutral beam system etc.) is required to achieve the 
steady state central cell density which has been calculated. Negative $\mathrm{I}_{\text {FUEL }}$ indicates an unphysical inbalance of the COLD ion flow rates since there are more particles entering the COLD population than are being lost. This can usually be remedied with the code model by lowering the test cell beta or lowering the axial confinement parameter $\left(n_{\tau}\right)_{C A}$.

\section{AUXILIARY MODELS}

Several additional models are needed to complete the description of tandem mirror test-cell configurations. Calculations which are described below include the charge exchange model for the test-ce 11 neutral beam injection, fusion reaction rate parameters $\langle\sigma\rangle_{H}$ for the hot mirror trapped ion distributions in the test cell and central cell, fractions of the alpha particle current and energy flux deposited in the halo and to the $v$ arious ion species and electrons, and modifications to the direct converter model to take into account axial loss of HOT* ions.

\subsection{Charge Exchange Mode 1}

Charge exchange and reionization of the neutral beam particies in the test cell region is included in the calculation of the required neutral beam current delivered. Calculations of the charge exchange current and the beam penetration current are done using analys is by $\mathrm{Carlson}$ and Hamilton. (9) The fractional charge exchange currents with and without the penetration current, as functions of beam injection energy are shown in Figs. 3 and 4 . The plasma attenuation parameter is given by

$$
\mathrm{Y}=2 \mathrm{r}_{\mathrm{p}} / \lambda_{\mathrm{T}}
$$

where $r_{p}$ is the plasma radius and $\lambda_{T}$ is the total mean free path for the injected neutral taking into account both ionization and charge exchange. The curves in Figs. 3 and 4 are input to the computer model by way of data statements. A two-dimensional linear interpolation is done to obtain the fractions for arbitrary energy and attenuation parameter. If $\boldsymbol{\gamma}$ is greater than 5.0 the mode? uses the analytic form originally given by Hovingh and Moir (10) 


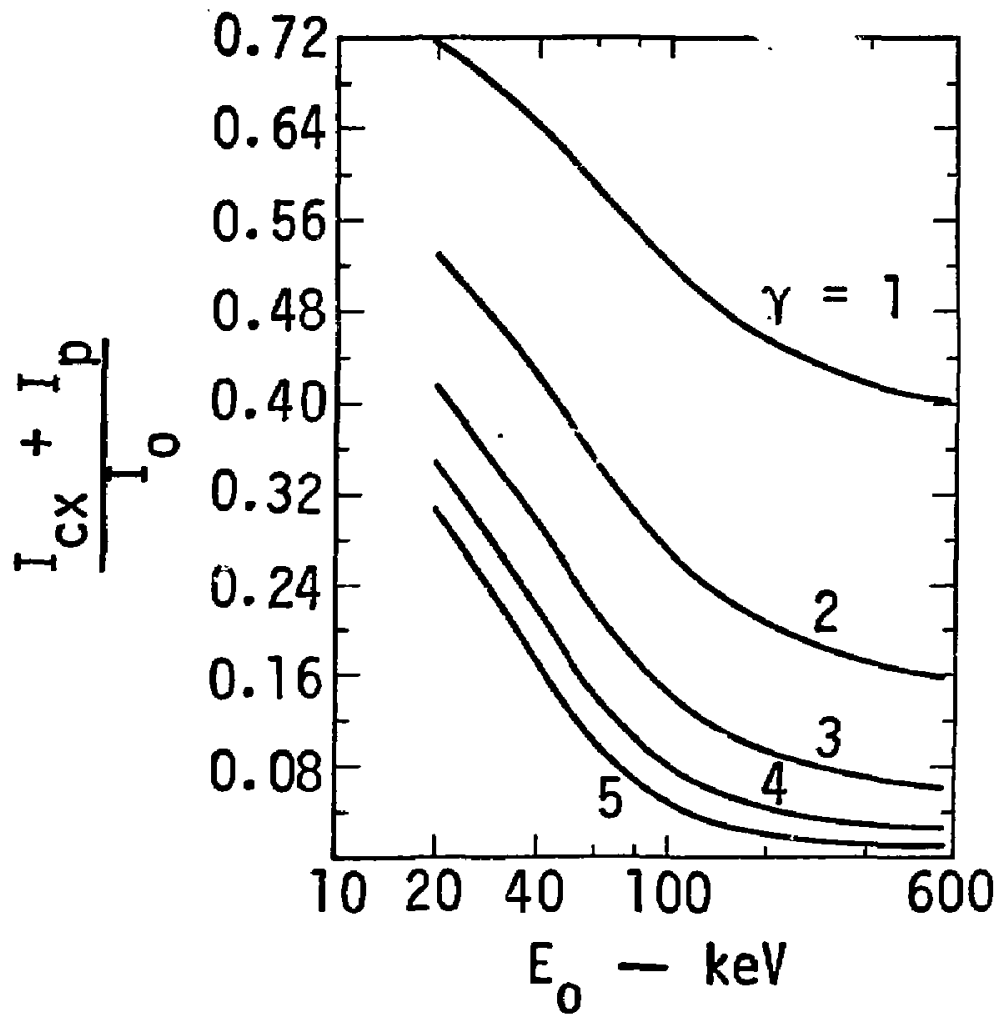

Fig. 3. Charge exchange $\left(I_{c x}\right)$ plus penetration $\left(I_{p}\right)$ current normalized to total delivered current $\left(I_{0}\right)$ as a function of plasma ion energy for various attenuation lengths $\gamma$ (from Ref. 9). 


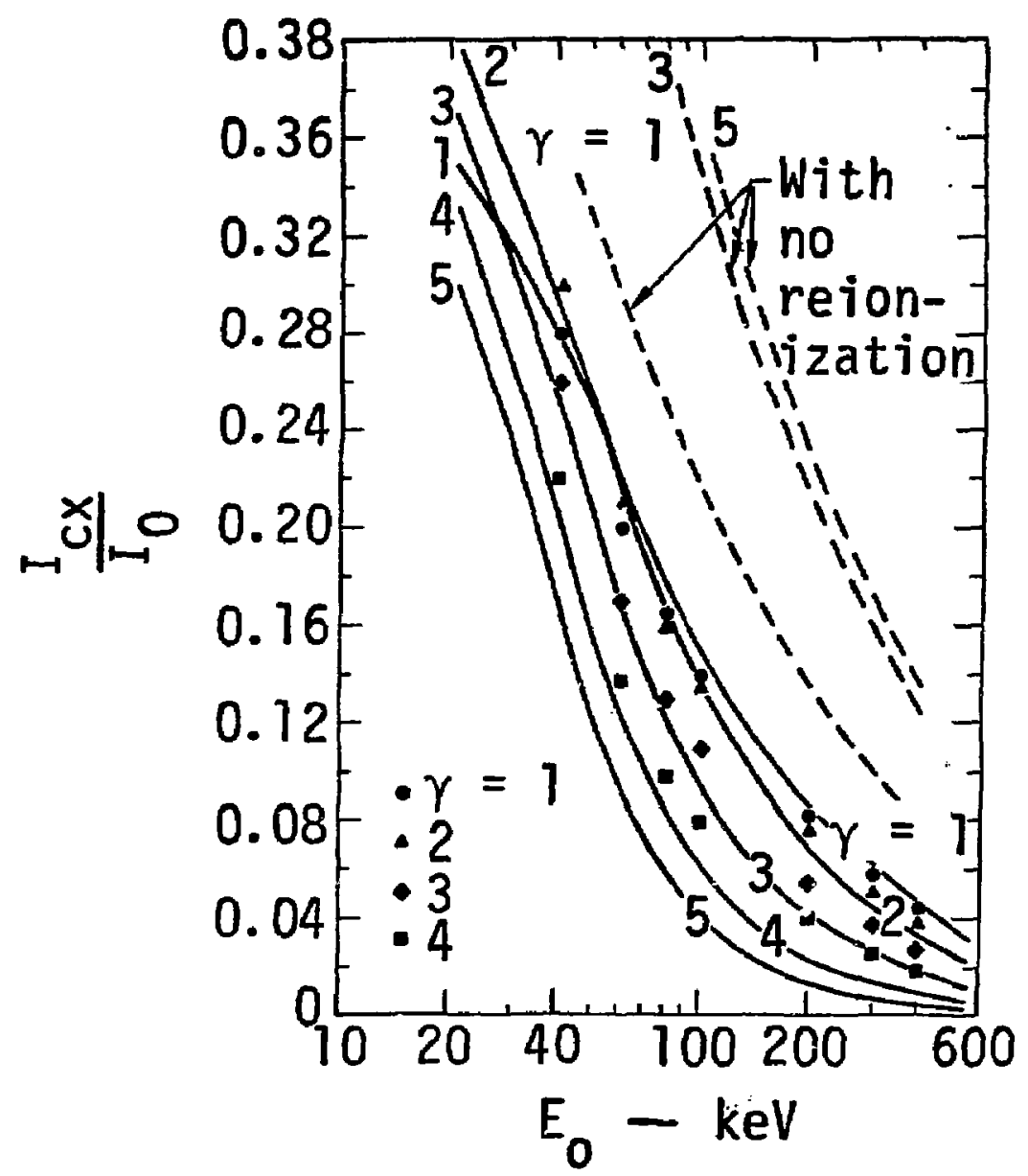

Fig. 4. Charge exchange current $\left(I_{C X}\right)$ normalized to total delivered current $\left(I_{0}\right)$ as a function of plasma ion energy for various attenuation lengths $\gamma$ (from Ref. 9). 


$$
\frac{I_{c x}}{I_{0}}=f_{c x} \frac{\langle\sigma V\rangle_{c x}}{\langle\sigma\rangle_{T}}\left(1-e^{-\gamma}\right) \exp \left[-\frac{\gamma}{2} \frac{\langle\sigma V\rangle_{i}}{\langle\sigma\rangle_{T}}\right]
$$

where

$$
\begin{aligned}
& \frac{\langle\sigma v\rangle_{i}}{\langle\sigma v\rangle_{T}}=0.184 \varepsilon_{0}^{0.29} \\
& \frac{\langle\sigma v\rangle_{C X}}{\langle\sigma v\rangle_{T}}=1-\frac{\left\langle\sigma v_{i}\right.}{\langle\sigma V\rangle_{T}}
\end{aligned}
$$

and

$$
E_{0}=\left(\frac{2}{2.5}\right) E_{I N J}
$$

The coefficient $f_{c x}$ has been adjusted so that the analytical formula gives the same results as the two-dimensional interpolation routines when $\gamma$ approaches 5.0. The studies so far have used $f_{c x}=0.75$.

\subsection{Hot Ion $\langle\sigma\rangle_{H}$ Parameters}

The fusion reaction rate parameters $\langle\sigma v\rangle_{H}$ for the HOT particles in the test cell and the HOT*'s in the central cell have been calculated by Marx et al. (11) The curves of $\langle\sigma\rangle_{H}$ as functions of the ion average energy for mirror ratios of 3 and 5 are shown in $F i g .5$. The data for $R_{m}=3$ has becn used in the studies so far. The curve is input to the computer model in data statements and a linear interpolation is used to obta in $\langle\sigma v(E)\rangle_{H}$ for arbitrary energy.

\subsection{Alpha Particle and Energy Coefficients}

The models presented in previous sections include several terms which describe both hot and thermal alpha effects in the test cell and central cell. Two auxiliary madels are required to calculate the coefficients in these terms. The first model determines the fractions of alpha particles and 

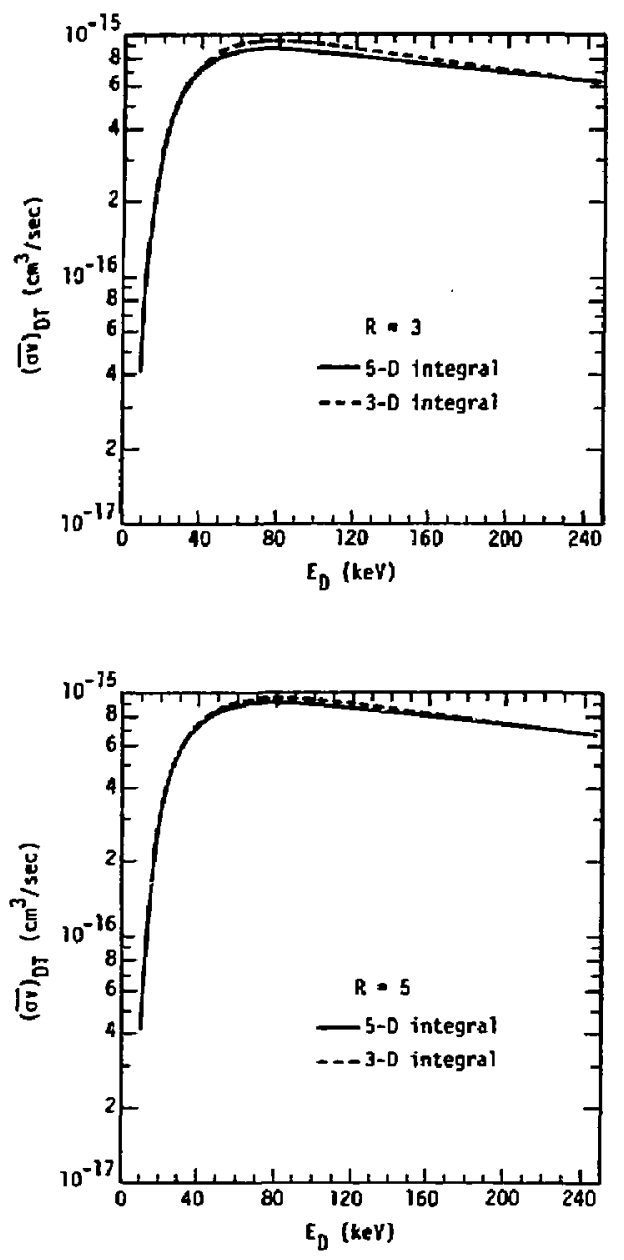

Fig. 5. Fusion reaction rate <ovs as a function of hot ion energy $\left(E_{D}\right)$ for mirror ratios, $R=3$ and $R=5$ (from Ref. 11 ). 
alpha energy which are deposited in the halo in the test cell and central cell. The second calculation determines fractions of alpha energy transferred to the ion species and electrons during slowing down.

The model of alpha deposition in the halo will be presented in detail in a separate report. (2) It includes effects due to alphas passing through the halo as well as non-adiabatic losses. The terms due to alphas pass ing through the halo are calculated separately for the test cell and central cell because they depend on the plasma radius and the magnetic field. The enhancenent of the alpha loss cone due to non-adiabatic effects depends on the electron density which is much larger in the test cell than in the central cell. Conb ining these effects yields coefficients $f_{\text {PART }}, f_{\text {ENERGY }}$, $f_{\text {PART }}^{m}$,

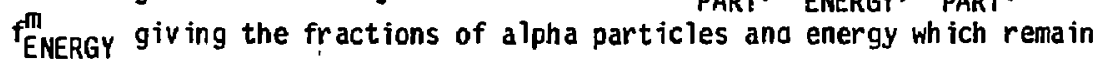
in the core plasma for the central cell and test cell, respectively.

The energy balances require fractions of hot alpha energy deposited in the ion populations and to electrons during slowing down. The fraction of hot alpha energy given to elections is given by

$$
f_{a, e}=0.88155 \exp \left(-T_{e c} / 67.4036\right)
$$

The available fractions of the total alpha power produced in the test cell and central cell are

$$
\begin{aligned}
& f_{\alpha, e m}=f_{\alpha, e} f_{\text {ENERGY }}^{m} \\
& f_{\alpha, e c}=f_{\alpha, e} f_{\text {ENERGY }}
\end{aligned}
$$

respectively. The available fractions for ions in the central cell are

$$
\begin{gathered}
f_{\alpha, C O L D}=\frac{f_{\alpha, i}{ }^{n_{c}}}{\left(n_{H}^{\star}+{ }^{n_{c}}\right)} \\
f_{\alpha, \text { HOT * }}=\frac{f_{\alpha, j} n_{H}^{\star}}{\left(n_{H}^{*}+n_{c}\right)}
\end{gathered}
$$

for the COLD and HOT* ions respectively, where

$$
f_{\alpha, i}=\left(1.0-f_{\alpha, e}\right) f_{\text {ENERGY }}
$$


Similarly in the test cell

$$
\begin{aligned}
f_{\alpha, C O L D}^{m} & =f_{\alpha, i}^{m} n_{c} \exp \left(-\phi_{m 0} / T_{c}\right) / d \\
: \quad f_{\alpha, H O T}^{m} & =f_{\alpha, i}^{m} n_{H} / d \\
f_{\alpha, H O T *}^{m} & =f_{\alpha, i}^{m} n_{H}^{*} / d
\end{aligned}
$$

for the COLD, HOT, and HOT* ions respectively where

$$
d=n_{H}+n_{H}^{*}+n_{c} \exp \left(-\phi_{m 0} / T_{c}\right)
$$

and

$$
f_{\alpha, i}^{m}=\left(1.0-f_{\alpha, e m}\right) f_{\text {ENERGY }}^{m}
$$

\subsection{Direct Converter Heat Flux}

In test cell configurations there may be appreciable axial loss of HOT* ions into the direct converter region. The additional particle flux into the direct converter is given by

$$
I_{H O T *}=\frac{q}{1000}[\text { TPTR3 }+ \text { TPTR4] }
$$

where

$$
\begin{aligned}
\text { TPTR3 }= & \overline{n_{H}^{\star} n_{e c}} c_{V X, H S L}\left(V_{C C}-V_{M O D}\right) /(m \tau)_{e i}^{*} \\
& +\overline{n_{H}^{\star} n_{e c}}\left(V_{C c}-V_{M 00}\right) /\left(n_{\tau}\right)_{i j}^{*}
\end{aligned}
$$




$$
\begin{aligned}
\text { TPTR4 }= & \overline{n_{H}^{*} n_{e m}} C_{V X}, H S L V_{M O D} /\left(n_{T}\right)_{e i}^{\star} \\
& +\overline{n_{H}^{\star} n_{e m}} V_{M O D} /\left(n_{\tau}\right)_{i j}^{\star}
\end{aligned}
$$

where the confinement parameters $(n \tau)_{j i}^{*}$ and $(n \tau)_{e i}^{*}$ are defined in EqS. (3.74) and (3.75), respectively, and the convection coefficient $C_{V X, H S L}=1.0-C_{V X, H S C}[$ see Eq. (3.92)]. The additional energy flux to the inner collector is given by

$$
H_{I C}^{*}=\left(1.0-f_{H S}\right) I_{H O T *}\left(\phi_{C}+\phi_{e}+\overline{E_{L, H O T}^{\hbar}}\right)
$$

and to the halo scraper

$$
H_{H S}^{*}=f_{H S} I_{H O T *}\left(\phi_{C}+\overline{E_{L}^{*}, H O T}+\frac{T_{e c}}{6.0}\right)
$$

where $f_{H S}$ is the fraction of the particle end loss which hits the halo scraper.

\section{USER'S GUIDE}

The test cell models described above have been incorporated in the TMRBAR tandem mirror reactor physics code. A brief guide to running test cel 1 cases is presented below. Some familiarity with operation of the standard TMRBAR code is assumed.

Test cell cases typically require more computer time than standard TMRBAR runs primarily because the number of physics balance equations to be solved is larger. In addition, the character of the device is very different when a test cell is used. Standard TMRBAR cases describe devices which are ignited so that solving the power balances for electrons and ions depends critically on the amount of alpha power which is deposited to these species. For test cell configurations the alpha production outside the test cell is usually much lower and the dominating terms in the central cell power balances are the drag terms from the hot ion species. Therefore, when running test 
cell cases care must be taken to begin with in itial values for the test cell parameters which are near the final solution. Of the central cell parameters, initial values for the electron temperature and the potential ratios $n_{e}=\phi_{e} / T_{e c}, n_{c}=\phi_{c} / T_{c}$, and $n_{b}=\phi_{b} / T_{e c}$ are the most important. Finally, the results will be sensitive to the test cell and central cell beta values, especially $\beta_{T C}$, so that solutions may not be obtainable for wide ranges of $\beta_{T C}$ and $\beta_{C}$.

Before proceeding to brief descriptions of the revised input and output files for the test cell mode 1 runs a short description of the present structure of the TMRBAR algorithm is required. Further details will be given in a separate report. (2) The code present]y solves the $N$ non-linear physics equations (in $N$ unknowns) which descr ibe the device simultaneously us ing a non- 1 inear equation solving library routine. Tandem mirror reactor cases use $N=14$. Devices with test ceil inserts are described by 20 equations. The library rout ine attempts to minimize the vector $\underline{R C}\left(\underline{X}^{k}\right)$ where, at the $k^{\text {th }}$ iteration

$$
\underline{R C}\left(\underline{X}^{k}\right)=\underline{R F}\left(\underline{X}^{k}\right)
$$

and $\underline{F}(\underline{X})=0$ defines the normalized solution vector $\underline{X}$ for the physics equations. In Eq. (6.1) $\underline{\underline{R}}$ is a diagonal matrix of normalization constants set to make $0.1 \leqslant R C_{j}\left(\underline{x}^{1}\right) \leqslant 1.0$ for $j=1, N$. The independent variable vector is also normalized so that $0.1<x_{j}<1.0$ for $j=1, N$. Some care must be given to proper choice of normalization constants for the components of $\underline{x}$. Some of the more important normalization constants may be set by input as described below. The normalizations for $\underline{R C}(\underline{x})$ are fixed in the code.

\section{1. Input Requirements}

A sample input file from a typical code run for MFTF- $\alpha+T$ parameters is given in Fig. 6. Test cell cases require two additional namelist input sections compared with standard TMRBAR runs. The first additional namelist (third name]ist in the input file) contains the test cell configuration parameters, initial values for the independent variables, test cell fixed 


\section{REPRODUCED FROM \\ BEST AVAILABLE COPY}

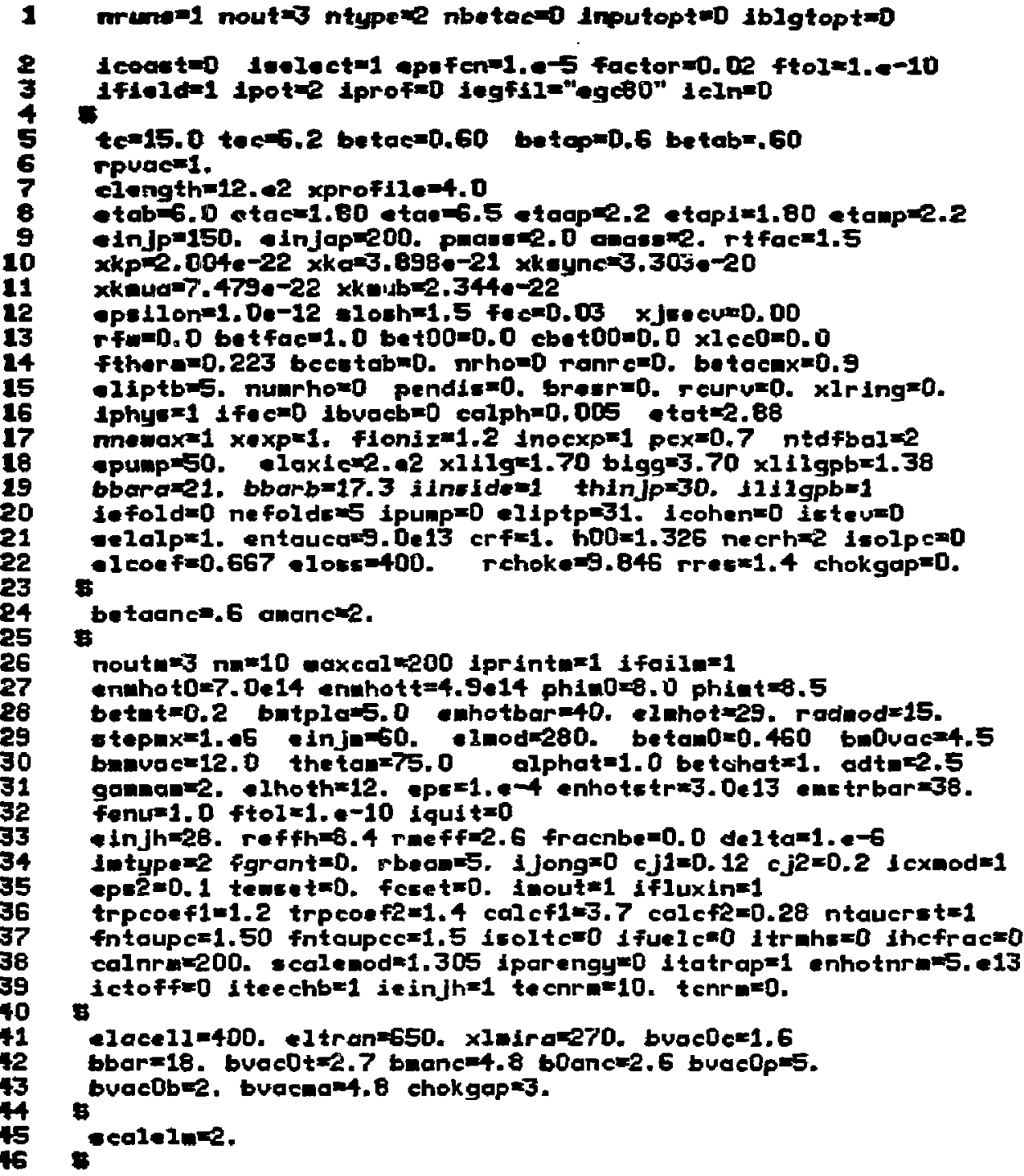

Fig. 6. Input file for the TMRBAR code calculation of the MFTF-at benchmark case (see Sec. 7.0). 
physics parameters (e.g., $\beta_{T C}$, $E_{\text {INJ }}$, etc.), and many variables which act as switches during the code run to select the model options to be used. The default options are always selected by setting the switch parameter to zero. Default normalizations are used if the normalization constants are set to zero. The test cell models are engaged by setting NTDFBAL $=2$. The available options are described in Appendix $A$.

The second additional namelist which may be included when running test cell cases gives magnetic field values at the device cardinal points and lengths of regions in the MARS-1 ike end cel1. This namelist is only engaged when NTDFBAL $=2$ and IF LUXIN $=1$. Current TMRBAR runs read magnetic field data from a binary input file generated by the EFFI magnetic field code. (12) In test cell cases for which there is no corresponding EFFI generated file available (e.g., in the MFTF-a+T study recently) an arbitrary EFFI file for another device must be used and the values then overwitten by the values input in the TFLUXIN field information namelist. This procedure will be streamlined in a future upgrade of the test cell code. For comparison, a sample input file descr ib ing FPD-II+T, for which there was a corresponoing EFF 1 generated input file, is given in Fig. 7 .

\subsection{Output File}

The output file generated from a test ceil run is similar to the standard TMRBAR output file. Because it is frequently more difficult to get convergence for test cell cases, an optian has been added which writes to the output file the value of

$$
\operatorname{RCNRM}=\left[\sum_{j=1}^{N} R C_{i}^{2}\left(\underline{x}^{k}\right)\right]^{1 / 2}
$$

at each iteration $k$. This option is engaged when NTDFBAL $=2$ and IMOUT $\neq 0$. The test cell results are given at the end of the standard TMRBAR output in a similar format. Finally, a summary list of test cell and central cell parameters is printed in a verticle column at the very end of the output file. Using the COLUMN 1 option in NETOUT puts this column of parameter values on a separate sheet from which it can be copied to form tables of parameters 


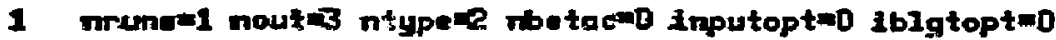

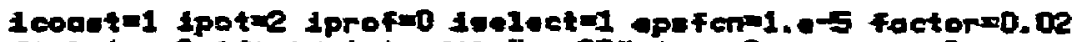
Ftol=1. -6 1fleld=1 logf11="egobo" leln=0 ineutrorte

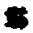

tc.24.9 tec:15. betack.36 betapm. 2475 betab-.45 rovace1. pmasere.0 amansez.

elength 00.22 xprofile 4,0

eteb-5.8 atac-3.0 atae-5.8 ntagp=1.55 -tap $1=1.2$ atamp=1.4

injp=300. Injap 280 . rtfac-1.5

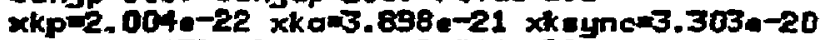

xkmuar7.479e-22 xkmub-2.344e-22

epe13on-1.De-12 sosh=1.3 fec=0.03 xjescum0.00

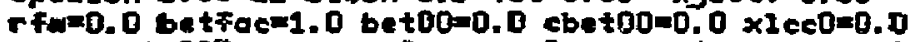

fther $=0.223$ becetab=0. nrho=0 rami $c=0$. betacax $=0.9$

aliptb-5. numrhom0 pendi=xo. braermo. reuru=0. xiring=0.

Iphys=1 $\lambda$ fec=0 ibuacb=0 calph=0.02 etatio. 3

mewax=1 ntdfbal=2 apupp 50 . 1 axic=2.-2

bbara-21. bbarb=17.3 x111g=2.3 bigg=4.3 x111gpb=1.38

fioniz $=1.2$ pex=0.7 inside=1 thinjp=30. ililgpb=1

1efold=0 nefolds 5 ipuap=0 eliptp=51. I cohen=0 isteun=0 inoexp=1

- elalp=1. xexp=1. entaued 3.07 e14 er $f=1$. hoo=1.68 necrh=2

5

$-1000 \neq 0.667$ rehoke=14. rres=1.4 chokgap $=-1$. 1solpe=0

betaanc=. 40 amancze?.

$\mathbf{8}$

noutm $=3$ nu=10 maxcal=200 1printm=1 ifallox=1

enwhot0.5. 0.14 ennhott=4.914 phim0x17 phimi=8.5

betint $=0.2$ batpia $=5.0$ enhotbar 65 . inhot 52 radnodu35.

-tepmx=1.e6 injo=75. elmodm750. betano=0.475 bnovac-4.69

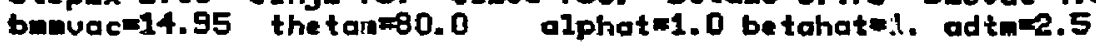
ganman-4. 0 elhoth-20 eps=1. De-8 enhotstr=4.5e12 enctrbar=55. fanum=1.0 $f \neq 01=1.9$-9 1 quit $=0$

injh=28. reffhm8.4 raeffm-2.6 fraenbe=0.0 delta=1.e-6

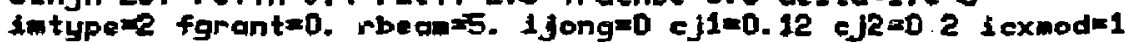
epse $=0.1$ tewset $t=0$. feset $=0$. Imout $t=1$ f luxin $=0$ trp coef $1=1.2$ trpcoe $f 2=1.4$ cal $c f 1=3.7$ sol cfl $=0.28$ ntaucrs $t=0$ ictoffeD fintaupe=1.5 fintaupce $=1.5$ isoltes iti. The $=0$ ihefrace calnrw $=30$. scalenod=1. b05 iparengy=0 itatrap=1 e.thotire-5. 13 \#

calein=2.

415

Fig. 7. Input file for a typical TMRBAR code calculation of parameters for FPD-II+T (see Ref. 4). 
for quick comparison of different code results. This became a valuable procedure during optimization studies of test cell performance over wide ranges of design parameters.

\subsection{Comments on Running}

A user's guide isn't complete without a little "hands on" experience from a previous user. The test cell code is admittedly not very user friendly at this writing. When difficulties arise the following general principles may be useful. First, use the debug utility DDT to monitor the progress of the code run until several successful runs are obtained which scope out the $r$ ange of parameter space in which there are solutions. Using SUB = FCN in DOT and monitoring the values of $\mathrm{RC}(1)$ to $\mathrm{RC}(20)$ will show how the convergence is progress ing. Runaway cases can usually be detected by monitor ing TC, TECU, EINGM, XLILG, and EMHOTBAR corresponding to variables $T_{c}, T_{e c}, \bar{E}_{I N J}, g$, and $\bar{E}_{H}$. Finally, if different initial guesses of the independent variables are being tried to get a case to converge, the general rule-of-thumb is to start with temperatures and potentials in the central cell and end cells which are slightly higher than the expected results. This seems to help the convergence process, possibly because the starting point represents a system with better confinement than the solution and thereby reduces the chances of runaway solutions.

\section{BENCHMARK CASE}

The test cell models incorporated in the TMRBAR code have been benchmarked (3) against calculations done for MFTF-a+T. (13) In particular, the operating parameters for MFTF- $\alpha+\mathrm{T}$ in the $\mathrm{High-F}$ (wall loading) mode have been calculated with the code model and compared witis the reference vaiues. In general the agreement is quite good and this verifies the accuracy of the code model. Specific differences between the code results and the reference values can be explained in terms of improved physics understanding of test-cell operation in tardem mirror devices which has 
occurred since the reference calculations were done. These points are described in detail in Ref. 3.

For this report a new benchmark case has been obtained using a different set of constraints than the case in Ref. 3. Again, the parameters from the reference calculation for MFTF- $\alpha+T$ in High- $\Gamma$ mode are given in Table 1. The new results from the code madel are given in Table 2. For this benchmark case the mirror-to-mirror and plasma effective lengths, peak and midplane on axis magnetic field values, peak and volume averaged beta values, and the plasma radius at the cardinal points used by the models were the same as the reference values in both the tesi cell and the remainder of the device. In addition, the COLD ion temperature and the test cell average injection energy have been fixed at the reference values. (Note that in Ref. 3

the test cell trapped current was fixed to the reference value and the average injection energy was variea to obtain energy balance.) Finally, the plug ion confining potential was varied [by varying the axial confinement parameter $(\mathrm{m})_{\mathrm{CA}}$ input to the code] to produce an operating point for which no supplemental fueling of the central cell would be required.

Comparison of the values in Tables 1 and 2 shows that with the constraints used for this benchmark case the present model yields an operating point with higher neutron wal1 loading $\left(\Gamma_{T C}=2.78 \mathrm{MW} /{ }^{2}\right.$ compared with $2.0 \mathrm{MW} / \mathrm{m}^{2}$ in the reference calculation) but the required test cell neutral beam power is also significantly higher $\left(P_{\mathrm{NB}, T C}=23.9 \mathrm{MW}\right.$ compared with $\left.14.4 \mathrm{MW}\right)$. As in the benchmark calculation from Ref. 3, the aditional neutral beam power is explained by the fact that direct losses of central cell particles due to pitch angle scattering from the Hot* population in to the loss cone have been included in the present models. Whereas the reference calculation attributed no particle losses to this mechanism, the benchmark case in Table 2 shows $132 \mathrm{~A}$ lost from the HOT* distribution. This combined with the $178 \mathrm{~A}$ of ions trapped in the transition region (pumped out by the drift pump system) and $65 \mathrm{~A}$ of axial loss current from the COLD population accounts for the required neutral beam trapped current in the test cell of $376 \mathrm{~A}$.

The orift pump current requirement is higher in the present case $(178 \mathrm{~A}$ compared with $97 \mathrm{~A}$ ) because the $\mathrm{g}$ value obtained with the present model (consistent with the particle, energy and potential calculations for the device 
Table 1. Basel ine parameters for MFTF-a+T High- $\Gamma$ mode from Ref. $T$.

\section{DT Test CeII}

\begin{tabular}{|c|c|c|c|}
\hline ПНОТ & $4.75 \times 10^{14} \mathrm{~cm}^{-3}$ & $P_{\text {FUS, TC }}$ & $11.0 \mathrm{MW}$ \\
\hline$\overline{E_{H O T}}$ & $40 \mathrm{keV}$ & $r_{p}$ & $15.0 \mathrm{~cm}$ \\
\hline$T_{e c}$ & $7 \mathrm{keV}$ & $r_{\text {WALL }}$ & $25.0 \mathrm{~cm}$ \\
\hline$\phi_{e}$ & $47 \mathrm{kV}$ & $\Gamma_{T C}$ & $2.0 \mathrm{~mW} / \mathrm{m}^{2}$ \\
\hline$\phi_{c}$ & $22 \mathrm{kV}$ & ${ }^{I_{T R A P}, T C^{\prime I}}{ }_{T C}$ & $190 \mathrm{~A} / 240 \mathrm{~A}$ \\
\hline$\left(n_{\tau}\right)_{\text {LOCAL }}$ & $2.0 \times 10^{13} \mathrm{~cm}^{-3} \mathrm{~s}$ & $P_{N B, T R A P} / P_{N B}$ & $1 T .4 \mathrm{MH} / 14.4 \mathrm{MW}$ \\
\hline$\angle O V D D$ & $6.6 \times 10^{-16} \mathrm{cn}^{3} / \mathrm{s}$ & $\overline{E_{I N J}}$ & $60 \mathrm{kel}$ \\
\hline$\Delta \phi_{T C}$ & $8.0 \mathrm{kV}$ & $\theta_{\text {INJ }}$ & $75^{\circ}$ \\
\hline$\hat{B}_{\mathrm{TC}}($ peak $)$ & 0.46 & & \\
\hline
\end{tabular}

Central Cell

\begin{tabular}{|c|c|c|c|}
\hline${ }^{n}{ }_{c}$ & $1.3 \times 10^{14} \mathrm{~cm}^{-3}$ & $r_{c}$ & $25.0 \mathrm{~cm}$ \\
\hline$n_{e c}$ & $1.6 \times 10^{14} \mathrm{~cm}^{-3}$ & $r_{\text {WALL }}$ & $45.0 \mathrm{~cm}$ \\
\hline$n_{H O T}^{*}$ & $3.0 \times 10^{13} \mathrm{~cm}^{-3}$ & $P_{\text {FUS }}$ & $5.9 \mathrm{MW}$ \\
\hline & $15.0 \mathrm{keV}$ & $\Gamma$ & $0.14 \mathrm{MW} / \mathrm{m}^{2}$ \\
\hline & $7.0 \mathrm{keV}$ & $c_{\alpha}$ & Negligible \\
\hline$=$ & $20.0 \mathrm{keV}$ & $I_{c, P A S T}$ & $90.0 \mathrm{~A}$ \\
\hline & $30.0 \mathrm{kV}$ & $\mathrm{I}_{\text {HOT } \star \text {,PAST }}$ & $O A$ \\
\hline & $39.0 \mathrm{kV}$ & I FUEL, COLD & $0 A$ \\
\hline peak) & 0.60 & & \\
\hline
\end{tabular}

Anchor

$\begin{array}{llll}n_{\text {PASS, ANC }} & 7.75 \times 10^{12} \mathrm{~cm}^{-3} & \overline{E_{H 0 T} \text {, ANC }} & 400 \mathrm{keV} \\ n_{\text {HOT, ANC }} & 2.4 \times 10^{13} \mathrm{~cm}^{-3} & P_{\text {ICRH }} & 1.14 \mathrm{MW} \text { (tota) }\end{array}$


Table 1. (cont inued).

\section{Transition}

$I_{\text {TRAP }}$

$I_{\text {NEO }}$

$\delta \phi_{t}$

Plug/Barrier

$\begin{array}{ll}n_{\text {PASS }}(b) & 3.0 \times 10^{12} \mathrm{~cm}^{-3} \\ n(b) & 12 \times 10^{13} \mathrm{~cm}^{-3} \\ g & 1.7 \\ G & 40 \\ n(a) & 2.3 \times 10^{13} \mathrm{~cm}^{-3} \\ \overline{E_{\text {eH }}} & 475 \mathrm{keV}\end{array}$

$n_{\text {PASS, }}$

$\mathrm{g}_{\mathrm{DT}}$

$\mathrm{H}_{\mathrm{DT}}$

IC $\mathrm{kV}$

$3 \mathrm{~A}$

$3.0 \times 10^{12} \mathrm{~cm}^{-3}$

$P_{\text {ECRH, b }}$

PECRH, a

$T_{\text {ew }}$

$\delta \phi a^{\prime} \rightarrow a$

$\delta \phi \mathrm{a}$

$\mathrm{R}_{E F F}, \mathrm{SLOSH}$

$n_{\text {SLOSH }} / n_{(b)}$
$1.2 \times 10^{13} \mathrm{~cm}^{-3}$

1.7

0.333

$1.08 \mathrm{MN}$ (total)

$0.12 \mathrm{MW}$ (total)

$60 \mathrm{keV}$

$37 \mathrm{kV}$

$60 \mathrm{kV}$

1.62

3.3 
Table 2. Base $\}$ ine parameters for MFTF- $\alpha^{+} T$ High- $\Gamma$ mode from present models.

\section{DT Test CeII}

\begin{tabular}{|c|c|c|c|}
\hline$n_{H O T}$ & $5.85 \times 10^{14} \mathrm{~cm}^{-3}$ & $P_{F U S, T C}$ & $16.5 \mathrm{MW}$ \\
\hline$\overline{\mathrm{E}_{\mathrm{HOT}}}$ & $36.5 \mathrm{keV}$ & $r_{p}$ & $15.0 \mathrm{~cm}$ \\
\hline$T_{e c}$ & $5.4 \mathrm{I} \mathrm{keV}$ & $r_{\text {WALL }}$ & $27.0 \mathrm{~cm}$ \\
\hline$\phi_{\mathrm{e}}$ & $39.3 \mathrm{kV}$ & $\mathrm{r}_{\mathrm{TC}}$ & $2.78 \mathrm{MW} / \mathrm{m}^{2}$ \\
\hline$\Phi_{c}$ & $26.2 \mathrm{kV}$ & $I_{T R A P, T C}{ }^{I} T C$ & $376 \mathrm{~A} / 398 \mathrm{~A}$ \\
\hline$(n \pi)_{\text {LOCAL }}$ & $1.84 \times 10^{13} \mathrm{~cm}^{-3} \mathrm{~s}$ & $\mathrm{P}_{\mathrm{NB}, T \mathrm{TC}^{\prime}} \mathrm{P}_{\mathrm{NB}}$ & $22.6 \mathrm{MH} / 23.9 \mathrm{MH}$ \\
\hline$\langle O V\rangle_{D T}$ & $6.39 \times 10^{-16} \mathrm{~cm}^{3} / \mathrm{s}$ & $\overline{E_{I N J}}$ & $60.0 \mathrm{keV}$ \\
\hline$\Delta \phi_{T C}$ & $7.50 \mathrm{kV}$ & ${ }^{\theta}$ INJ & $75^{\circ}$ \\
\hline$\hat{\beta}_{T C \text { (peak) }}$ & 0.46 & & $\therefore$ \\
\hline
\end{tabular}

Centra $1 \mathrm{Cel} T$

\begin{tabular}{|c|c|c|c|}
\hline$n_{c}$ & $1.56 \times 10^{74} \mathrm{~cm}^{-3}$ & $r_{c}$ & $26.7 \mathrm{~cm}$ \\
\hline$n_{e c}$ & $1.74 \times 10^{74} \mathrm{~cm}^{-3}$ & $r_{\text {WALL }}$ & $59.8 \mathrm{~cm}$ \\
\hline$n_{\text {HOT }}^{*}$ & $1.88 \times 10^{13} \mathrm{~cm}^{-3}$ & $P_{\text {FUS }}$ & $6.66 \mathrm{MW}$ \\
\hline $\mathrm{T}_{\mathrm{c}}$ & $15.0 \mathrm{keV}$ & $\Gamma$ & $0.12 \mathrm{MW} / \mathrm{m}^{2}$ \\
\hline$\underline{T} \underline{\underline{e c}}$ & $5.41 \mathrm{keV}$ & $c_{\alpha}$ & $7.1 \times 10^{-4}$ \\
\hline$E_{H}^{*}$ & $36.6 \mathrm{keV}$ & $I_{c, P A S T}$ & $66.3 \mathrm{~A}$ \\
\hline$\phi_{i \mathrm{C}}$ & $33.7 \mathrm{kV}$ & $I_{\text {HOT*, PAST }}$ & $132.0 \mathrm{~A}$ \\
\hline$\phi_{\mathrm{ec}}$ & $31.8 \mathrm{kV}$ & $I_{\text {FUEL, }}$ COLD & $0.0 \mathrm{~A}$ \\
\hline$\hat{B}_{c(p e a k)}$ & 0.60 & & \\
\hline
\end{tabular}

Anchor

$\begin{array}{llll}n_{\text {PASS, ANC }} & 2.88 \times 10^{12} \mathrm{~cm}^{-3} & \overline{E_{\text {HOT }} \text {, ANC }} & 1187 \mathrm{keV} \\ n_{\text {HOT, ANC }} & 1.07 \times 10^{13} \mathrm{~cm}^{-3} & P_{\text {ICRH }} & 0.707 \mathrm{MW} \text { (total) }\end{array}$


Tab7e 2. (cont inued).

\section{Transition}

$\begin{array}{llll}I_{\text {TRAP }} & 178 \mathrm{~A} & \mathrm{n}_{\text {PASS }, \mathrm{t}} & 4.17 \times 10^{12} \mathrm{~cm}^{-3} \\ \mathrm{I}_{\text {NEO }} & 0.79 \mathrm{~A} & \mathrm{~g}_{\text {DT }} & 1.27 \\ \delta \Phi_{\mathrm{t}} & 18.9 \mathrm{kV} & H_{\text {DT }} & 1.13\end{array}$

Plug/Barrier

$\begin{array}{llll}n_{P A S S}(b) & 1.66 \times 10^{12} \mathrm{~cm}^{-3} & P_{E C R H, b} & 1.50 \mathrm{MW} \text { (total) } \\ n(b) & 5.43 \times 10^{12} \mathrm{~cm}^{-3} & P_{E C R H, a} & 0.089 \mathrm{MH} \text { (tota) } \\ g & 1.27 & T_{e W} & 22.8 \mathrm{keV} \\ G & 3.27 & \delta \phi_{\mathrm{a}^{\prime} \rightarrow \mathrm{a}} & 46.9 \mathrm{kV} \\ \mathrm{n}(\mathrm{a}) & 8.75 \times 10^{12} \mathrm{~cm}^{-3} & \delta \phi_{\mathrm{a}} & 63.9 \mathrm{kV} \\ \overline{E_{\mathrm{eH}}} & 1339 \mathrm{keV} & R_{E F F, S L O S H} & 1.40 \\ & & n_{S L O S H / n(b)} & 2.64 \\ \end{array}$


as a whole) is on $7 y$ 1.27. The trapping current strongly depends on the product $K_{\text {TRAP }}$ TASS, $^{2} / T_{c}^{3 / 2}$ where

$$
K_{\text {TRAP }}=H \frac{g^{10 / 3}}{(g-1)^{7 / 3}}
$$

(see Refs. 1 and 8). Therefore, at fixed $T_{c}$, even though the present model finds a lower passing density in the transition (due to the energy cutoff described in Ref. 3), the trapping current is much larger than in the reference case because the factor $K_{\text {TRAP }}$ is much larger $\left(K_{\text {TRAP }}=53.2\right.$ compared with 4.5).

Finally, the higher wall loading in the present case results from higher HOT ion density in the test cell. This can be explained by the fact that HOT ion orag on COLD ions has been included in the present models. This energy loss mechanism from the HOT population results in lower HOT ion average energy (36.5 keV compared with $40 \mathrm{keV}$ ) than in the reference case. At fixed test cell beta this results in higher test cell ion density. In addition, sirce HOT ion drag on electrons dominates the electron power balance the electron temperature is also lower than the reference value $(5.4 \mathrm{kel}$ compared with $7.0 \mathrm{keV})$. Since confinement parameters for the HOT particles scale with $\mathrm{T}^{3 / 2}$ and the required neutral beam current to the test cell is proportional to $n^{2} /\left(n_{\tau}\right)$, higher test cell density and lower electron temperature yield much higher beam current ( $376 \mathrm{~A}$ compared with $190 \mathrm{~A}$ ) in the present case.

Other differences between the reference values and those given in Table 2 can be explained by the improvements to the physics mode 1 in the present calculation as described in Ref. 3 .

\section{SUMMARY}

This section serves two purposes. First, conclusions are presented for the test cell modeling which is described in this report and for the benchmark of the code in which they are implemented. Second, several areas for future work which have been identified during the development of the current models are described. 


\section{B.1. Conclusions}

Models of the energy and particle balance for a high-field technology test cell operated in the central cell of a tandem mirror have been developed. In the models the test cell is treated as a separate subsystem with potential referenced to the central cell potential. Hot mirror trapped populations in both the test cell and central cell regions are considered. Interactions between these hot particles and the Maxwellian electrons and ions in the central cell are included. The relative potential at the midplane of the test cell is calculated consistently from a quasi-neutrality condition.

The particle and energy balances for the HOT mirror trapped ions in the test cell and the HOT* mirror trapped ions in the central cell are caiculated separatejy. Both are formulated in terms of a Logan-Rensink plug model for neutral beam injection into a mirror cell with a potential. The net flow of particles across the velocity space boundaries separating the different populationns is crudely modeled.

Hot alpha effects due to alphs born from HOT-HOT reactions and HOT*-HOT* reactions in the test cell and central cell are included in the particle and energy balances of all the ion species and the electrons. The current of alphas from these reactions is also included in the alpha particle balance which affects the drift pumping requirements in tine transition and indirectly the loss rate of DT ions due to drift purning.

Finally, the balance of ions for the entire device includes fueling of the central cell Maxwellian plasma by a fraction of the ions injected into the test cell region. In addition, the axial loss of HOT* particles from the central cell due to pitch angle scattering out of the central cell mirror trap at energies above the electrostatic confining potential is modeled. The axial loss of HOT* ions is included in calculations of the heat flux to the components of the direct converter.

\subsection{Future Work}

Two major areas for future work have been identified during the course of developing the test-cell models. First, the Logan-Rens ink models used to 
calculate energy balance for the HOT and HOT* particles need to be calibrated over a range of parameters rather than the single point calibration which has been available so far. Second, the model of net particle flow across the bounaaries in velocity space which separate the ion populations needs to be reformulated in terms of the slope of the distribution on the boundary (or some model of it) rather than the number of particles on the boundary. These areas are described in more detail below. Some minor changes have been noted in this report and others are given below.

Calibration of the Logan-Rens ink formulation used in the hot ion models is required because the Logan-Rens ink model does not take into account partial filling of the loss cone for the hot ions by the background Maxwellian distribution in the central cell. The single point calibration which has been done so far resulted from comparison of Logan-Rensink predictions with multi-region Fokker-P lanck models of test cell configurations (see Sec. 3.3). The confinement parameters ( $n \tau$ ) in the Logan-Rensink model depend strongly on the electron temperature and the average injection energy so that some scaling of the calibration coefficient with these quantities would improve the moael. In addition, the conf inement resuits from Fokker-Planck models are expected to show some dependence on the amount the loss cone is filled by the background ions. Since this dependence is not explicitly given in the Logan-Rens ink formulation the effect might be accounted for by having the calibration coefficient be a function of the COLD density. Work continues in this area us ing the HYBRID-I I Fokker-Planck code $(14,15)$ to obtain confinement results over a range of parameters. Typicaliy th is code requires far less computer time than the multi-region Fokker-P lanck model.

The improvements which are necessary in the model of particle flow across velocity space boundaries y require significant effort. At this point it may be worth considering ' 1 alternative approach involving a change in the categorization of particle populations in velocity space. Instead of separating HOT* ions from COLD trapped particles in the central cell by a ficticious boundary, the natural model would combine these ions into one class of central cell WARM trapped particles. This has not been done yet because the formulas which calculate the density of passing ions in the end cells do so by mapping from a Maxwellian distribution in the central cell. To model 
the ions in the central cell region for test-cell configurations as a WARP trapped population would require new mapping formulas for the end cell passing ions. The development work required for this compared with that required to improve the flow rate model is a tradeoff under consideration at th is time.

Finally, minor changes required in the model have been indicated in Secs. 3 and 4 . Several other model improvements should be added in future upgrades of the code. The charge exchange model (Sec. 5.1) requires further adjustment of $i_{c x}$ to produce results which vary smoothly going from the fits of the data to the analytic model as YDT increases above 5 . In addition, the charge exchange results should be included in the power balance of the HOT particles by adding an additional power source term to the balance equation [Eq. (3.19)] of the form

$$
T R 38=I_{C X}\left(\bar{E}_{\text {INJ }}-\bar{E}_{\text {HOT }}\right)
$$

The Logan-Rensink model takes into account only sources to the power balance from beam particle current equal to the loss current from the mirror cell. Equation (8.1) represents the power source to the HOT population when a HOT ion with average energy $E_{H}$ is replaced by a beam particle with average energy $\bar{E}_{I N J}$ due to a charge exchange event. A final improvement would be to develop a mode] which relates the density-squared effective length

$$
L_{\text {eff }}=\frac{B_{0}}{n_{0}^{2}} \int \frac{d z n^{2}(z)}{B(z)},
$$

required for power balance calculations, with the flux tube effective length $\hat{L}_{\text {eff }}=B_{0} s d z / B(z)$, for mirror distributions of the type found in the test cel1. The applications studied thus far have used simple scaling arguments to calculate $L_{\text {eff }}$ based on MFTF- $\alpha+T$ results. 
Several options are available in the test-cell version of the TMRBAR code both for changing the structure of the solution process (e.g., variables which are fixed vs those which are solved) and for changing particular aspects of the models. The options currently in use are descr ibed below. Each is identified by the variable from the input file which acts as a switch to engage or disengage the option.

\section{A.1. NORMALIZATIONS}

The following variables control the normalization of independent $v a r i a b l e s$ in the solution vector $\underline{x}$. In each case default normalization constants are used if the contral variable is set to zero. Switch

variable

\section{Description}

CALNRM $\neq 0 \quad$ Normalization of alpha concentration $C_{\alpha}$ such that $\mathrm{XC}(3)=\mathrm{C}_{\alpha}$ * CALNRM.

ENHOTNRM $\neq 0 \quad$ Normalization of HOT* density $n^{*}$ such that $x C(19)=n_{H}^{\star} /$ ENHOTNRM.

TECNRM $\neq 0$ Normalization of electron temperature $T_{e c}$ such that $\mathrm{XC}(1)=\mathrm{T}_{\text {ec }} /$ TECNRM.

TCNRM $\quad \neq 0$ Normalization of ion temperature $T_{C}$ such that $X C(3)=T_{c} / T C N R$.

PMONRM $\neq 0 \quad$ Normalization of test cell potential $\phi_{m 0}$ such that $X C(16)=\phi_{m} /$ PMONRM. 


\section{A.2. CALCULATION OPTIONS}

These switch variables control either the structure of the solution process or options in the physics model. Default options are obtained by setting the switch variaile equal to zera.

Switch

variable

Description

ISOLTC $=0$

Solve for $g$ (XLILG) with $T_{C}\left(T_{C}\right)$ and $\overline{E_{I N J}}$ (EINJM)

fixed by input.

$=7 \quad$ Solve for $T_{C}$ with $g$ and $\overline{E_{I N J}}$ fixed.

$=2$ Solve for $\overline{E_{\text {INJ }}}$ with $g$ and $T_{C}$ fixed.

ITRMHS $=0$ Include convection model to calculate fractions of HOT and IHCFRAC $=0\}$ HOT* particles which go to COLD population.

$\neq 0\}$ Assume that all HOT losses become HOT* particles and all

$\neq 0\}$ HOT* losses become COLD particles before being lost from the device.

IEINJH $=0$ Assume HOT losses entering the COLD distribution carry an average energy of $3 / 2 T_{c}$.

$=1$ HOT losses entering the COLD distribution carry average energy of $\phi_{C}$.

ICXMOD $=0$ Inc?ude charge exchange losses of the neutral beam particles injected into the test cell.

$=1$ Assume all beam particles delivered to the test cell are trapped in the plasma. 


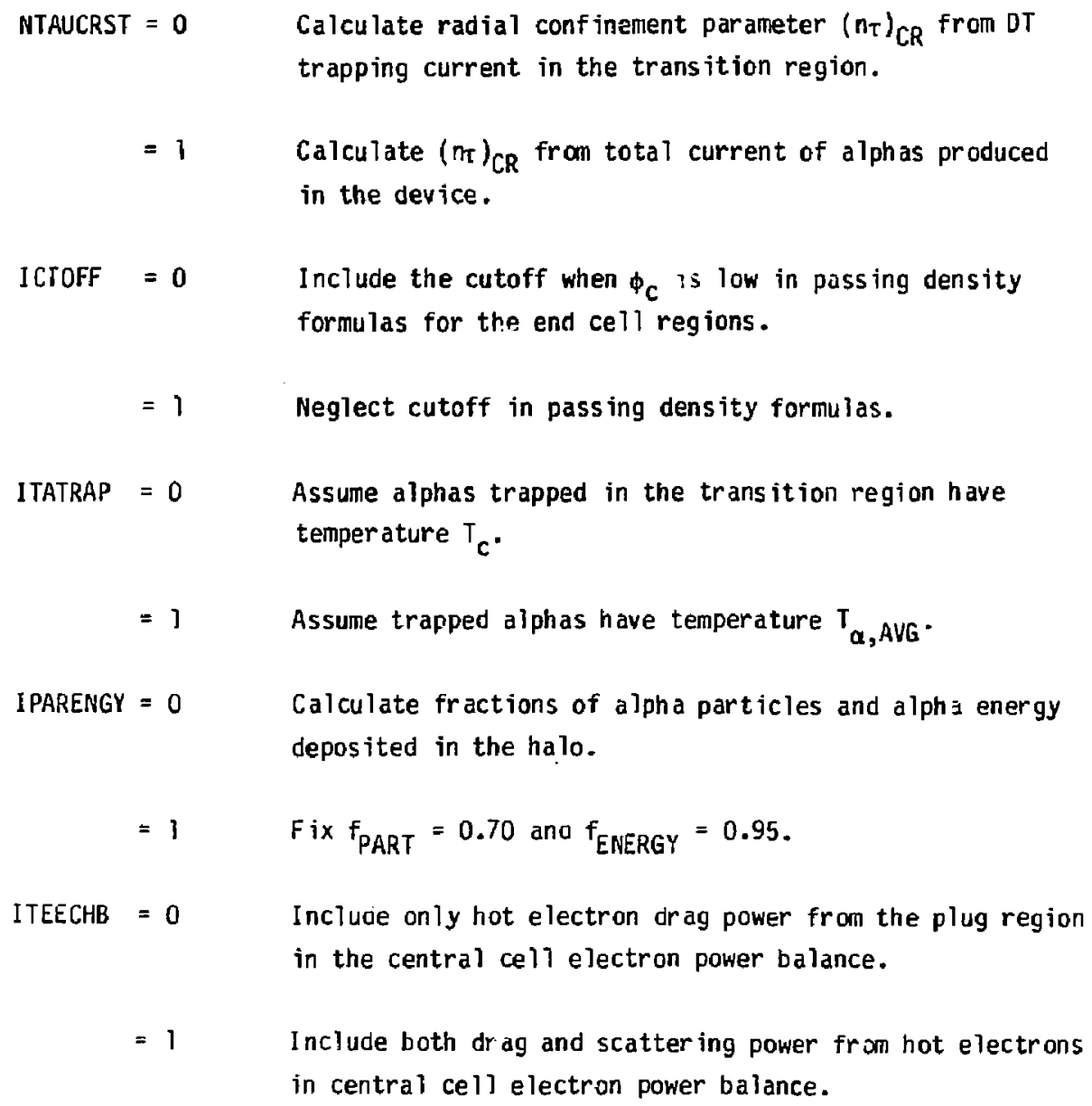

$=1$ Include both $\mathrm{drag}$ and scattering power from hot electrons in central cell electron power balance. 
1. R. B. Campbe11, TMRBAR - A Code to Calculate P lasma Par ameters for Tandem Mirror Reactors Uperating in the MARS Mode, Lawrence Livermore National Laboratory, Livermore, CA, UCID-19875, August 1983.

2. R. B. Campbell and $M$. E. Fenstermacher, to be published.

3. M. E. Fenstermacher and R. B. Campbe11, Modeling and Opt imization of MFTF- $\alpha+T$ High- $\Gamma$ Mode Performance, Lawrence Livermore Nat iona 1

Labor atory, Livermore, CA, UCI0-20284, December 1984.

4. S. H. Haney and M. E. Fenstermacher, Test Cell Modeling and Optimization for FPD-II, Lawrence Livermore National Laboratory, Livermore, CA, UCIO, March 1985.

5. G. A. Carlson et aI., Tandem Mirror Reactor with Thermal Barriers, Lawrence Livermore National Laboratory, Livermore, CA, UCRL-52836, September 1979, pp. 48-50.

6 B. C. Logan, A. A. Mirin, and M. E. Rensink, "An Analytic Model for Classical Confinement in Tanden Mirror Plugs," Nuc. Fus. 20, 1613 (1980).

7. Y. Matsuda and J. J. Stewart in Proc. of the 10 th Conf on Numerical Solutions of Plasmas, San Diego, Januairy 4-6, 1983 (GA Technologies Inc., San Diego, 1983) Paper 2BB.

8. A. H. Futch and L. L. LoDestro, Collis ional Trapping Rates for Ions in a Magnetic and Potential wel1, Lawrence Livermore National Laboratory, Livermore, CA, UCRL-872,9g (F eb. 1982).

9. G. A. Car7son and G. W. Hami] ton, Wall Bombardment Due to the Charge Exchange of Injected Neutrals with a Fusion Plasma, Lawrence Livermore National Laboratory, Livermore, CA, UCRL-75306, Apri] 1974.

10. J. Hovingh ano R. W. Moir, Efficiency of Injection of High Energy Neutral Beams into Thermonuclear Reactor 5 , Lawrence Livermore Mational Laboratory, Livermore, CA, UCRL-5 1419 (Ju1y 1973).

1i. K. A. Marx, A. A. Mirin, M. G. McCoy, M. E. Rensink, and J. Killeen, "Calculatien of (ov) DT $_{\text {for An isotropic Mirror and Toroidal }}$ Distr ibut ions," Nuc. Fus. 16, 702 (1976). 
12. S. J. Sackett, EFFI - A Code for Calculating the E lectromagnetic Field, Force, and Inductance in Coils Systems of Arbitrary Geometry User's Manual, Lawrence Livermore National Laboratory, Livermore, CA, UCID-17621, May 5, 1977.

13. K. I. Thomassen and J. N. Doggett, Eds., Options to Upgrade the Mirror Fusion Test Facility, Lawrence Livermore National Laboratory, Livermore, CA, UCID-19743, April 1983.

14. J. Killeen, A. A. Mirin, and M. E. Rensink, "The Solution of the Kinetic Equation for a Mult ispecies Plasma, "Methods of Computational Physics, 16, $389(1976)$.

15. A. A. Mirin, Lawrence Livermore National Laboratory, private communication. 